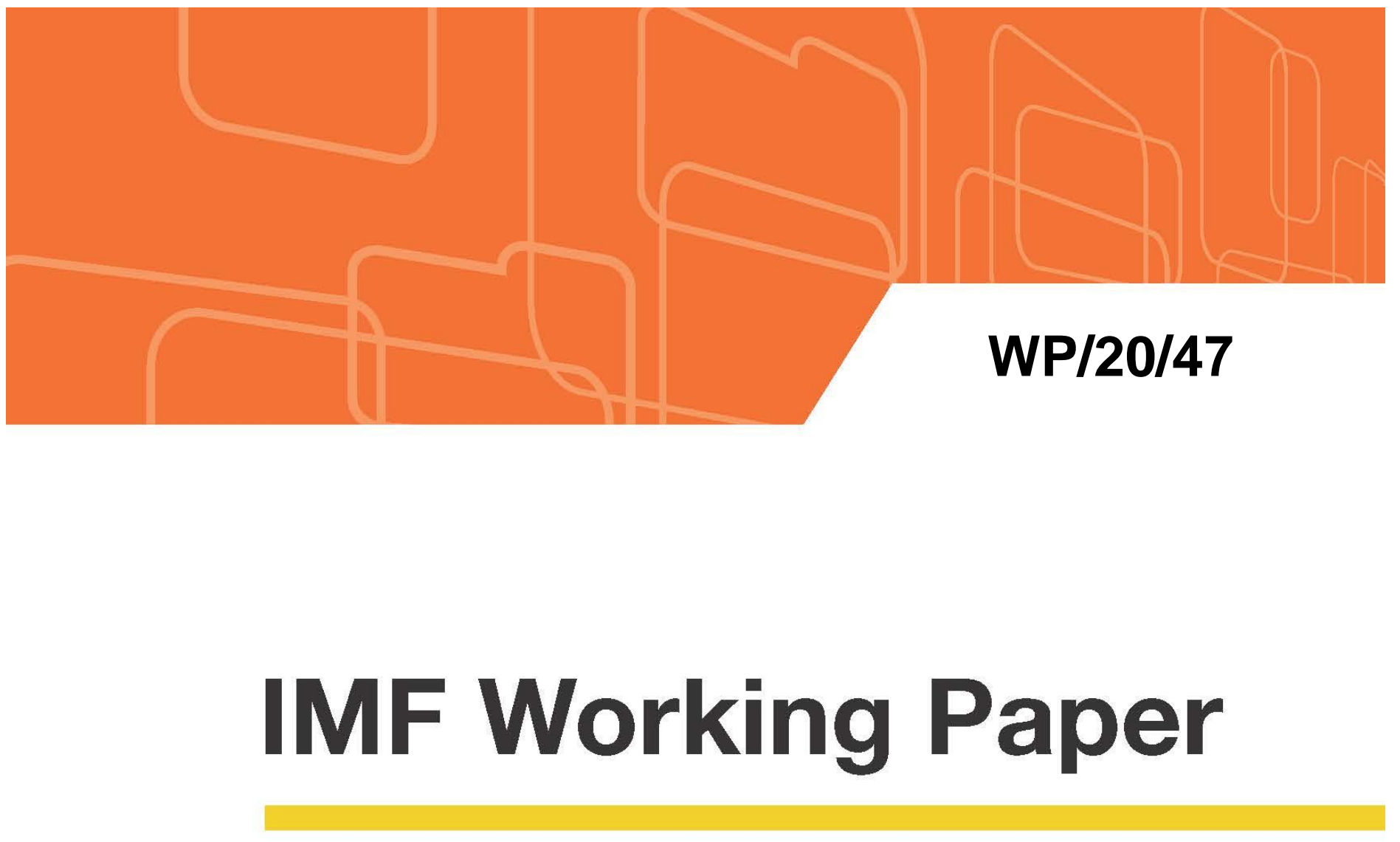

\title{
Transitory and Permanent Shocks in the Global Market for Crude Oil
}

by Nooman Rebei and Rashid Sbia

IMF Working Papers describe research in progress by the author(s) and are published to elicit comments and to encourage debate. The views expressed in IMF Working Papers are those of the author(s) and do not necessarily represent the views of the IMF, its Executive Board, or IMF management.

$$
\text { I N T E R N A T I O N A L M O N E T A R Y F U N D }
$$




\title{
IMF Working Paper
}

Middle East and Central Asia Department

\section{Transitory and Permanent Shocks in the Global Market for Crude Oil ${ }^{1}$ Prepared by Nooman Rebei and Rashid Sbia}

Authorized for distribution by Jean-François Dauphin

February 2020

\section{IMF Working Papers describe research in progress by the author(s) and are published to elicit comments and to encourage debate. The views expressed in IMF Working Papers are those of the author(s) and do not necessarily represent the views of the IMF, its Executive Board, or IMF management.}

\begin{abstract}
This paper documents the determinants of real oil price in the global market based on SVAR model embedding transitory and permanent shocks on oil demand and supply as well as speculative disturbances. We find evidence of significant differences in the propagation mechanisms of transitory versus permanent shocks, pointing to the importance of disentangling their distinct effects. Permanent supply disruptions turn out to be a bigger factor in historical oil price movements during the most recent decades, while speculative shocks became less influential.

JEL Classification Numbers: Q41, Q43, C32, E32, G28

Keywords: Oil market, Vector autoregressions, Narrative analysis, Bayesian estimation, Kalman filtering

Author's E-Mail Address: nrebei@imf.org and rasbia@mof.gov.ae
\end{abstract}

\footnotetext{
${ }^{1}$ We thank for comments Reda Cherif, Jean-François Dauphin, James Hamilton, Fuad Hasanov, Akito Matsumoto, and Andrea Pescatori.
} 


\section{Contents}

1 Introduction $\quad 5$

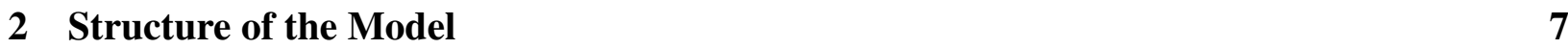

2.1 Measuring global activity . . . . . . . . . . . . . . . . 7

2.2 Transitory and permanent shocks . . . . . . . . . . . . . . . 9

2.3 Identification Restrictions . . . . . . . . . . . . . . . . . . . . 10

2.4 Priors and estimation $\ldots \ldots \ldots \ldots \ldots \ldots$

3 Empirical Results $\quad 12$

3.1 Impulse-response functions . . . . . . . . . . . . . . . . . . 13

3.2 Variance decomposition . . . . . . . . . . . . . . . . 17

3.3 Conditional correlations . . . . . . . . . . . . . . . . . . 19

3.4 Historical decomposition of oil prices . . . . . . . . . . . . . 20

4 Iterative Estimation $\quad 24$

4.1 Variance decomposition . . . . . . . . . . . . . . . . . 24

4.2 Oil price reaction to speculative shocks $\ldots \ldots \ldots \ldots$

5 Robustness Check $\quad 27$

6 Conclusion $\quad 29$

$\begin{array}{ll}\text { A Data Sources } & 34\end{array}$

A.1 Global real activity . . . . . . . . . . . . . . . . 34

A.2 Oil market variables . . . . . . . . . . . . . . . . . 35

B Unit Roots and Cointegration $\quad 36$

B.1 Unit Roots . . . . . . . . . . . . . . . . . . . 36

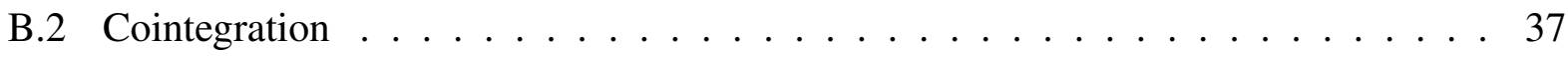

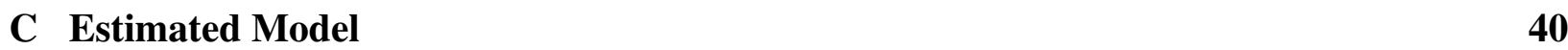

\section{List of Figures}

1 Trends in the Global Economic and Oil Activities . . . . . . . . . . . . . 8 
2 Prior versus Posterior Distributions . . . . . . . . . . . . . . . . . . . . . . . . . 14

3 Impulse-Response Functions _ . . . . . . . . . . . . . . . . . 16

4 Historical Decomposition of Oil Prices . . . . . . . . . . . . . . . . 23

5 Change in the Variance Decomposition of Oil Prices . . . . . . . . . . . 25

6 Change in the Standard Deviations . . . . . . . . . . . . . . . 26

7 Change in the Response of Oil Prices to a Speculative Shock . . . . . . . . . . 27

8 Impulse-Response Functions . . . . . . . . . . . . . . . . . . 28

A.1 Historical Data . . . . . . . . . . . . . . . . . . . 36

\section{List of Tables}

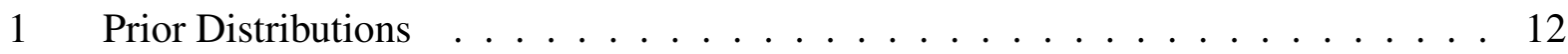

2 Variance Decomposition . . . . . . . . . . . . . . . 18

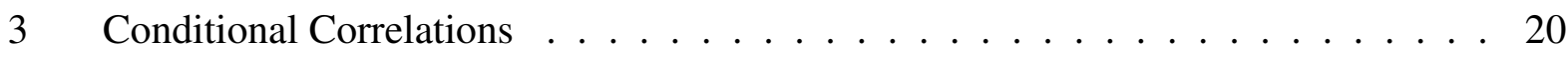

A.1 Clemente-Montanes-Reyes Unit Root Test with Structural Breaks . . . . . . . 37

A.2 Cointegration: Oil Variables _ . . . . . . . . . . . . . . . . . 38

A.3 Cointegration: Oil Variables + Global GDP . . . . . . . . . . . . . . . . . . . 39 


\section{Introduction}

A central question in macroeconomics concerns the role of supply and demand shocks in the international market of crude oil and their impact on price determination. The conclusions reached in the literature range from demand shocks being the main driver of oil price fluctuations (e.g., Kilian, 2009a; Lippi and Nobili, 2012), to supply shocks being the prominent source (e.g., Hamilton, 2009; Blanchard and Galí, 2010); while others find that the two sources of fluctuations are playing equally important role in explaining oil prices and oil quantities (see for instance Caldara et al., 2018). Using data on oil inventory, Juvenal and Petrella (2015) and Knittel and Pindyck (2016) find a pronounced contribution of speculation disturbances to the crude oil spot price movements. The identification scheme of the structural shocks is key to understand the roots of oil price swings, including the recent price plunge since the second half of 2014. Once again, the literature draws different conclusions, which are generally tributary to the structure of the model and identification strategy. On the persistence of global oil market shocks, several experts advocate in favor of a long-lasting (permanent) impact of the recent shock on oil prices (see for instance Cherif et al., 2017; Sommer et al., 2016) especially in the wake of the recent sharp decline in oil prices (mid2014); however, the existing literature did not empirically test this premise as none of the studies explicitly distinguishes transitory and permanent shocks in the proposed empirical setups.

While we still attempt to identify the sources of fluctuations of oil market variables, the present paper departs from the existing literature in two innovative dimensions. First, we model the sources of non-stationarity in the empirical model based on rigorous identification of the roots of cointegration between the endogenous variables while accounting for structural breaks. In particular, we simultaneously allow for permanent and transitory supply and demand shocks to compete in the econometric estimation. ${ }^{1}$ Second, to better capture the demand side aspects, we introduce a straightforward variable capturing global activity; namely we build series of global real GDP at purchasing power parity in US dollars on a quarterly basis for the OECD plus 5 other major countries: Brazil, China, India, Indonesia, and South Africa. The inclusion of this variable is key in the present paper especially in the context of assessing the impact of permanent versus transitory shocks. We believe that accounting for other activities than the industrial sector (captured by the aggregated industrial production index as proposed by Baumeister and Hamilton, 2018) and the tradable sector (approximated by using an indicator of shipping capacity derived by Kilian,

\footnotetext{
${ }^{1}$ To the best of our knowledge this is the first attempt to introduce the permanent dimension in a multi-variate model of the global oil market. In a recent paper, Leduc et al. (2016) use the Kalman filter to infer the permanent and transitory components of shocks to spot oil prices in the context of a univariate specification.
} 
2009b), would be important to our analysis. This is particularly important as large long-term shifts in the structure of the production have been witnessed during the recent decades (e.g., the predominance of the service sector, the increasing efficiency in oil consumption, and the diversification of sources of energy) in conjunction with permanent innovations (and disruptions) in the oil industry (e.g., fracking, long-lasting conflicts and oil production disruptions, and significant oil discoveries).

This paper is also related to a body of work that incorporates speculative shocks in the set of structural innovations and their identification, along with the transitory supply and demand shocks, which is achieved via restrictions of prior distributions inspired from a methodology pioneered by Uhlig (2005) and adopted by Uribe (2018) in the context of transitory and permanent monetary shocks.

Interpreting global activity and oil market variables fluctuations under the lens of our model reveals several interesting results. Over the period extending from 1974Q1 to 2018Q1, a quarter of the global GDP long term volatility is attributed to transitory and permanent shocks to oil supply as well as the speculative innovations. Interestingly, oil price fluctuations are predominantly driven by the same three oil market specific shocks; while global activity does not yield any significant volatility of oil prices. We would argue that this result is consistent with the observed negative unconditional correlation between the two variables. Despite the relevance of speculative shocks over the long sample - a third of the oil price volatility is imputed to speculation — the results of the iterative estimation reveal that their contribution has been weakening owing to a falling dynamic propagation mechanism of the speculative innovations during the most recent periods.

Several empirical results are worth noting. Surprisingly, the oil production impulse-response function following a permanent demand shock is negative and remain below zero for several quarters along with an oil inventory buildup. Two possible interpretations could be inferred. One explanation may be that the permanent component of the global activity encompasses technological innovations and the introduction of alternative sources of energy. The alternative explanation would be the decline in the share of oil-dependent economic activities. Further, looking at two particular historical episodes, i.e., 2008 and 2014, the model estimates rule out the attribution of the observed oil price plunge to global demand shocks (as previously reported by Kilian and Murphy, 2014; Caldara et al., 2018; Prest, 2018). Alternatively, the empirical results of the model reveal that the 2008 (2014) price decline was caused by unexpected positive permanent (transitory) oil supply shock, where the speculative shocks played a minor role consistently with the dynamics of oil inventories. Besides, the demand shocks transmission to oil prices were inconsequential. 
As a robustness check exercise, we reestimate the benchmark model allowing the global activity to be measured as the aggregated industrial production index proposed by Baumeister and Hamilton (2018). This analysis serves not only to assess the empirical results obtained with the constructed global GDP, but also to find the rationale behind the negative response of oil production to a shock to the trend of global activity. We find evidence of declining share of the industrial production, which turns out to be the major source of the negative correlation between global production and global activity conditional on permanent demand shocks. All the other results of the benchmark model remain virtually unchanged.

The rest of this paper is organized as follows. Section 2 presents the empirical framework as well as the identification strategy and data description. Section 3 lays out the main empirical results, while Section 4 applies the empirical methodology to the context of a rolling-window estimation and highlights the main sensitive results to change in the sample. In Section 5, we conduct some robustness exercises. Finally, Section 6 concludes.

\section{Structure of the Model}

Our premise is that global oil market variables could react differently to transitory and permanent shocks. Accordingly, we propose a vector autoregressive model with unobserved components with the objective of capturing the dynamics of four economic indicators; namely, the logarithm of real global activity, denoted $x_{t}$, the logarithm of global crude oil production, denoted $z_{t}$, the logarithm of oil inventories, denoted $i_{t}$, and the logarithm of the real price of crude oil, denoted $p_{t}$. All data are quarterly and seasonally adjusted with a sample period extending from 1974q1 to $2018 \mathrm{q} 1$.

\subsection{Measuring global activity}

Note that a unique indicator capturing the global activity is not available per se and some additional calculations are generally involved. In a seminal paper, Kilian (2009b) proposes using the cost of shipping to construct an alternative proxy for global economic activity, which was subsequently adopted in several studies (e.g., Antolín-Díaz and Rubio-Ramírez, 2018; Gambetti and Moretti, 2017; Juvenal and Petrella, 2015; Ratti and Vespignani, 2015). ${ }^{2}$ Hamilton (2018) suggests that the Kilian (2009b) index mischaracterizes particular episodes of economic downturn, and proposes an

\footnotetext{
${ }^{2}$ Kilian (2009b) assumes that growth in shipping capacity, improvements in shipping productivity, and growth of potential real GDP could be characterized by deterministic time trends; then, he proxies the cyclical component of global real economic activity with the residuals from a regression of the real cost of shipping on a time trend.
} 
alternative measure based on an estimate of monthly industrial production for the OECD plus 6 other major economies. ${ }^{3}$ Notwithstanding, the rationale behind considering the industrial production as a good proxy for aggregate output is only valid if the value added by industrial production represents a substantive share of total production across countries. Figure 1a shows that the share of services has grown considerably in most economies and currently accounts for at least half of the total production activity in most advanced and merging countries, which challenges the adoption of the industrial production index as a "good" proxy the economic activity.

\section{Figure 1: Trends in the Global Economic and Oil Activities}

(a) Industrial sector in Global Activity

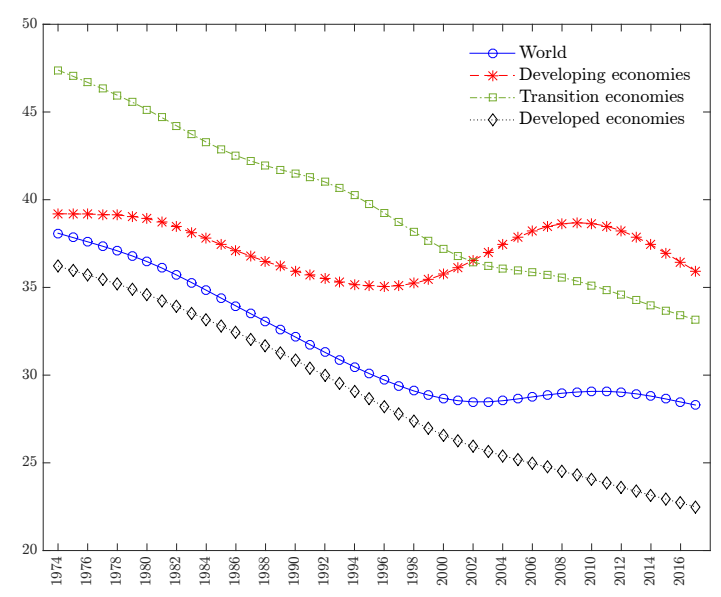

(b) Oil Consumption in Global Activity

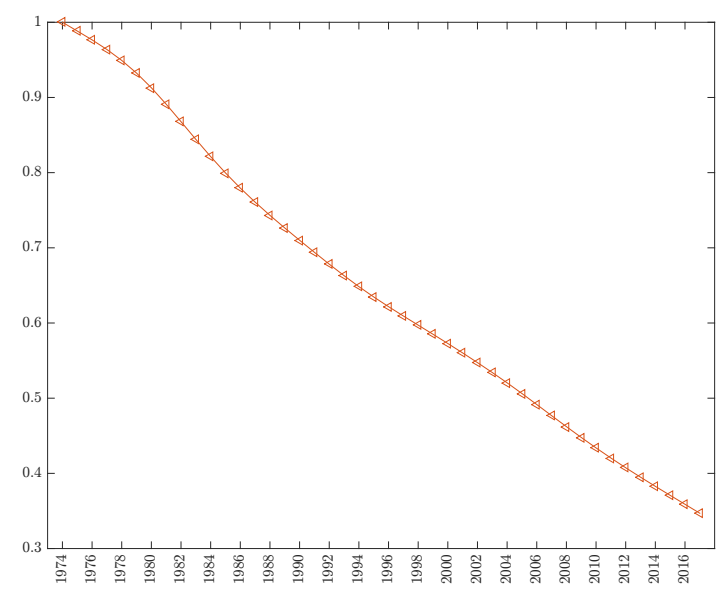

This issue is particularly key in our analysis as we propose to identify transitory versus permanent shocks. One can expect that permanent changes in the structure of the economy - higher share of services in total production - should impact the dynamics of the global oil market. Figure $1 \mathrm{~b}$ illustrates the decline in the share of oil consumption in total production over time, which could result from technological innovations, resulting in less dependence on oil as an input for production, and/or a change in the structure of total production (less industrial activities and more services). To capture the structural changes in the economic and oil activities, we refrain from

\footnotetext{
${ }^{3}$ Although Kilian (2009b) indicator was adopted by several other papers, Hamilton (2018) argues that this series misrepresents the recent fluctuation in global activity showing a drop in world economic activity in 2016 that was far more severe than that in either the financial crisis of 2008-2009 or the 1974-75 global recession.

${ }^{4}$ Further to the issue of declining correlation between the industrial production index and aggregate economic activity, the OECD series ends in $2011 \mathrm{~m} 10$. Baumeister and Hamilton (2018) reproduced the methodology by which the original index was constructed to extend the series.
} 
using proxies that exclusively mimic movements in the industrial activities and propose a new measure of global real GDP (at purchasing power parity) in US dollars on a quarterly basis for the OECD plus 5 other major countries (Brazil, China, India, Indonesia, and South Africa). Quarterly real GDP time series for the 5 other major countries became available only during the 1990s; appendix A.1 describes the methodology used to infer the quarterly observations during the previous periods. The resulting estimate of the aggregate real production in the OECD plus 5 is plotted in Figure A.1.

\subsection{Transitory and permanent shocks}

In the context of our analysis, we are particularly interested in explaining the source of long-term trends as well as the cyclical dynamics of the variables. Hence, we assume that the four endogenous variables are driven by five exogenous shocks: a nonstationary oil supply, denoted $\Psi^{s}$; a stationary oil supply shock, denoted $\phi^{s}$; a stationary speculative shock, denoted $\phi^{s p}$; a nonstationary demand shock, $\Psi^{d}$; and a stationary demand shock, denoted $\phi^{d}$.

According to the cointegration tests, as described in appendix B, the variables specific to the global oil market - i.e., oil production, inventories, and prices - have unit roots and share the same nonstationarity component (see Tables A.1 and A.2). The applied test also identifies 1980Q3 as break date in the data. Further, global activity is not cointegrated with the oil sector specific variables (see Table A.3). Accordingly, we assume that oil production, inventories, and prices are cointegrated and share a common trend, $\Psi^{s}$; and the global output trend is explained by an independent variable $\Psi^{d}$. One can then define the following vector containing stationary variables

$$
\left[\begin{array}{c}
\hat{x}_{t} \\
\hat{z}_{t} \\
\hat{i}_{t} \\
\hat{p}_{t}
\end{array}\right] \equiv\left[\begin{array}{c}
x_{t}-\Psi_{t}^{d} \\
z_{t}-\Psi_{t}^{s} \\
i_{t}-\Psi_{t}^{s} \\
p_{t}-\Psi_{t}^{s}
\end{array}\right]
$$

We assume that the law of motion of the vector of endogenous variables takes the standard autoregressive form

\footnotetext{
${ }^{5}$ While we are interested in identifying shock particular to the global crude oil market, the shocks $\Psi^{d}$ and $\psi^{d}$ are meant to capture the nonstationary and stationary components of combinations of non-oil disturbances of different natures, such as technology shocks, trade shocks, or fiscal shocks, which our analysis is not intended to individually identify.
} 


$$
\left[\begin{array}{c}
\hat{x}_{t} \\
\hat{z}_{t} \\
\hat{i}_{t} \\
\hat{p}_{t}
\end{array}\right]=\sum_{i=1}^{L} A_{i}\left[\begin{array}{c}
\hat{x}_{t-1} \\
\hat{z}_{t-1} \\
\hat{i}_{t-1} \\
\hat{p}_{t-1}
\end{array}\right]+B\left[\begin{array}{c}
\Delta \Psi_{t}^{s} \\
\phi_{t}^{s} \\
\phi_{t}^{s p} \\
\Delta \Psi_{t}^{d} \\
\phi_{t}^{d}
\end{array}\right]
$$

where $\Delta \Psi_{t}^{s} \equiv \Psi_{t}^{s}-\Psi_{t-1}^{s}$ and $\Delta \Psi_{t}^{d} \equiv \Psi_{t}^{d}-\Psi_{t-1}^{d}$ denote changes in the nonstationary shocks. The transition matrices $A_{i}$, for $i=1, \ldots, L$, are 4-by-4 matrices of coefficients, $B$ is a 4-by-5 matrix of coefficients, and $L$ is a scalar denoting the lag length.

We assume that the structural shocks follow univariate AR(1) laws of motion where we consider one dummy variable to account for particular changes in the trend of the oil market variables as identified in the cointegration analysis. ${ }^{6}$ Formally, the transitory and permanent components evolve according to

$$
\left[\begin{array}{c}
\Delta \Psi_{t+1}^{s} \\
\phi_{t+1}^{s p} \\
\phi_{t+1}^{s} \\
\Delta \Psi_{t+1}^{d} \\
\phi_{t+1}^{d}
\end{array}\right]=\kappa d_{t+1}+\rho\left[\begin{array}{c}
\Delta \Psi_{t}^{s} \\
\phi_{t}^{s} \\
\phi_{t}^{s p} \\
\Delta \Psi_{t}^{d} \\
\phi_{t}^{d}
\end{array}\right]+\omega\left[\begin{array}{c}
\varepsilon_{t+1}^{1} \\
\varepsilon_{t+1}^{2} \\
\varepsilon_{t+1}^{3} \\
\varepsilon_{t+1}^{4} \\
\varepsilon_{t+1}^{5}
\end{array}\right]
$$

where $\kappa$ is a 5-by- 1 matrix; $\rho$ and $\omega$ are 5-by-5 diagonal matrices; and $\varepsilon_{t}^{i}$ are i.i.d. normally distributed disturbances.

\subsection{Identification Restrictions}

According to the cointegration test exercises, four identification assumptions have been introduced, namely, that oil production, inventories and prices are cointegrated with $\Psi_{t}^{s}$, and the global output is cointegrated with $\Psi_{t}^{d}$. Furthermore, to identify the different transitory shocks, we adopt a methodology pioneered by Uhlig (2005) and impose sign restrictions on the effect of the disturbances on endogenous variables. Operationally, we have to decide on the horizon - number of quarters - the sign restrictions used for identification should hold. In this regard, Canova and Paustian (2007) show that sign restrictions imposed on the contemporaneous relationships among variables are robust to several types of model misspecification. Following this approach, we impose the sign

\footnotetext{
${ }^{6}$ In a similar context, Perron and Wada (2009) show that running the data through a Kalman filter while ignoring structural breaks would lead to false conclusions in terms of the cyclical component.
} 
restrictions only on impact. In particular, all sign restrictions involve weak inequalities and allow for the responses to be zero. Specifically, we assume that:

- Transitory oil-supply shock: $B_{1,2} \geq 0, B_{2,2} \geq 0$, and $B_{4,2} \leq 0$

- Transitory speculative shock: $B_{1,3} \leq 0, B_{2,3} \geq 0$, and $B_{4,3} \geq 0$

- Transitory demand shock: $B_{1,5} \geq 0, B_{2,5} \geq 0$, and $B_{4,5} \geq 0$

According to the above restrictions, we define as a transitory oil-supply shock one that causes the oil production and its real price to move in opposite directions, and increases the global activity. A speculative shock is one that generates a positive response of the oil production and its price, and reduces the global activity. A positive transitory shock to the global oil demand is one that induces positive correlations between the oil production, its price, and inventories. the real oil price. Finally, without loss of generality, we introduce the normalizations $B_{1,5}=B_{2,2}=B_{3,3}=1$.

\subsection{Priors and estimation}

Table 1 describes the prior distributions of the model's parameters. Concerning the prior distributions, we assume a specification that has a Minnesota prior flavor, the most commonly adopted macroeconomic priors for the VAR coefficients. These priors express the premise that an independent random-walk model for each variable in the system is a reasonable process for the beliefs about their time series behavior. The prior also assumes that lags of other variables are less informative than own lags, and that most recent lags of a variable tend to be more informative than more distant lags. Formally, the coefficients in the diagonal of the matrix $A_{1}$ are a priori independent and normally distributed, with means and standard deviations set to 0.8 and 0.15 , respectively. Furthermore, we choose flat prior distributions for the $B$ matrix coefficients capturing the contemporaneous reaction of the endogenous variables to structural shocks - gamma (normal) distributions with mean values set to $1(0)$ and standard destinations equal to 1 - in accordance with the sign restriction identification assumptions. The prior serial correlations of the shocks are assumed to have relatively low means of 0.3 and standard deviations of 0.15 . Finally, we assume normal prior distributions for the standard errors of the structural shocks.

In order to identify the lag length of the autoregressive block, we proceed with the posterior odds comparisons of competing model with lags from 1 to $6 .^{7}$ To draw from the posterior distributions of the estimated parameters, we apply the Metropolis-Hastings sampler to construct a

\footnotetext{
${ }^{7}$ The posterior odds ratio test largely prefers the model with $\mathrm{L}=2$, which implies a Log data density of 1766.8 , considerably higher than the outcome of the other alternative models (e.g., 1649.6 with $\mathrm{L}=4$ ).
} 
Monte-Carlo Markov chain (MCMC) of 500,000 draws after burning the initial 20 percent draws. Posterior means and error bands around the impulse responses shown in the next section are constructed from a random subsample of the MCMC chain of length 100,000 with replacement.

Table 1: Prior Distributions

\begin{tabular}{llll}
\hline \hline Parameter & Distribution & Mean & Std. Dev. \\
& & & \\
\hline$A_{1}(j, j)$ for $j=1$ to 4 & Normal & 0.8 & 0.15 \\
$A_{i}(j, k)$ for $i=2, \ldots, L$ & Normal & 0 & 0.25 \\
$B_{1,2}$ and $-B_{1,3}$ & Gamma & 1 & 1 \\
$B_{2,3}$ and $-B_{1,5}$ & Gamma & 1 & 1 \\
$-B_{4,1},-B_{4,2}, B_{4,3}$, and $B_{4,5}$ & Gamma & 1 & 1 \\
Other elements of $B$ & Normal & 0 & 1 \\
$\kappa_{1,1}$ & Normal & 0 & 1 \\
$\rho(j, j)$ for $j=1$ to 4 & Normal & 0.3 & 0.15 \\
$\omega(j, j)$ for $j=1$ to 4 & Normal & 1 & 0.25 \\
\hline
\end{tabular}

\section{Empirical Results}

Figure 2 displays posterior distributions of the matrix $B$ elements. In general, the results show that the data is informative on the model parameters as the posterior distributions are noticeably different from the prior ones. The first row exhibits the contemporaneous impact of shocks on the global real activity, where sign restrictions are imposed conditional on the transitory oil supply and the speculative shocks $\left(B_{1,2} \geq 0\right.$ and $\left.-B_{1,3} \geq 0\right)$. The posterior averages for the two parameters are around 0.13 , significantly lower than the prior assumption. Interestingly, the global activity is rather irresponsive to permanent oil market specific shocks. It is worth noting that the posterior mean of the parameter $B_{1,4}$, estimated at -0.36 , still reflects a short-term positive reaction of global activity to a permanent demand shock as the corresponding variable in the estimated model is defined as $\hat{x}_{t}=x_{t}-\Psi_{t}$. Consequently, the global activity should mildly react to the permanent shock, at a lower response than the impulse shock, before subsequently reaching the new steadystate level.

The two constrained parameters governing the immediate reaction of oil availability are those 
corresponding to the speculative and transitory global demand shocks with posterior means estimated at 0.27 and 0.43 , respectively. Although the contemporaneous effect of the permanent oil market shock is somewhat counter-intuitive showing a negative response on impact - negative posterior mean of $B_{2,1}$ - the impulse-response function would, by construction, quickly build over time before reaching a new positive steady state. With regard to the permanent global activity shock, the result is somehow surprising as it reflects a negative contemporaneous reaction of oil production, which warrants some additional discussion.

The posterior means of the third and fourth row elements of the matrix $B$ are broadly intuitive. However, it is noteworthy that the data moves the prior towards higher absolute values reflecting the large volatility of oil inventories and real prices. We refer to the next section for further discussions on the implications of the estimated values of $B_{i, j}$.

\subsection{Impulse-response functions}

Figure 3 plots the posterior modes of the impulse-response functions of each of the endogenous variables following a one percent unexpected increase in the structural shocks included in $\varepsilon_{t}$. Oil supply shocks (transitory versus permanent) are shown to have broadly similar qualitative effects on the variables while exhibiting difference in the periods where the highest impact is registered as well as the amplitude of the responses. Transitory supply shocks yield a larger contemporaneous effect on the real price of oil and oil production compared to the effect of permanent supply shocks. The real price reaction dissipates after 10 quarters in the transitory shock case, whereas oil availability significantly remains above its long-term level for about five years. An important aspect to notice in this panel is that following the permanent oil supply shock, global output eventually rises to a higher medium-run level, though it does not rise significantly above zero until about eight quarters following the shock with a maximum impact of 0.4 percent. Furthermore, the cumulative response of the global output following a permanent innovation in the oil market is significantly larger than the case of a transitory shock, pointing to the importance of explicitly distinguishing between the two types of shocks. If fact, this result turns out to be crucial in the interpretation of the historical episodes of oil price swings as the identification of the shocks triggering those fluctuations are dependent on the perception of the magnitude and persistence of the implied global activity trajectory. Note that oil inventories tend to react in an opposite fashion, as they strongly react contemporaneously and slowly decline to below zero in the subsequent periods. Interestingly, the same occurs following a transitory oil supply shock as both global output and the stock of oil increase on impact while the latter registers a persistent positive response as opposed to the former, 


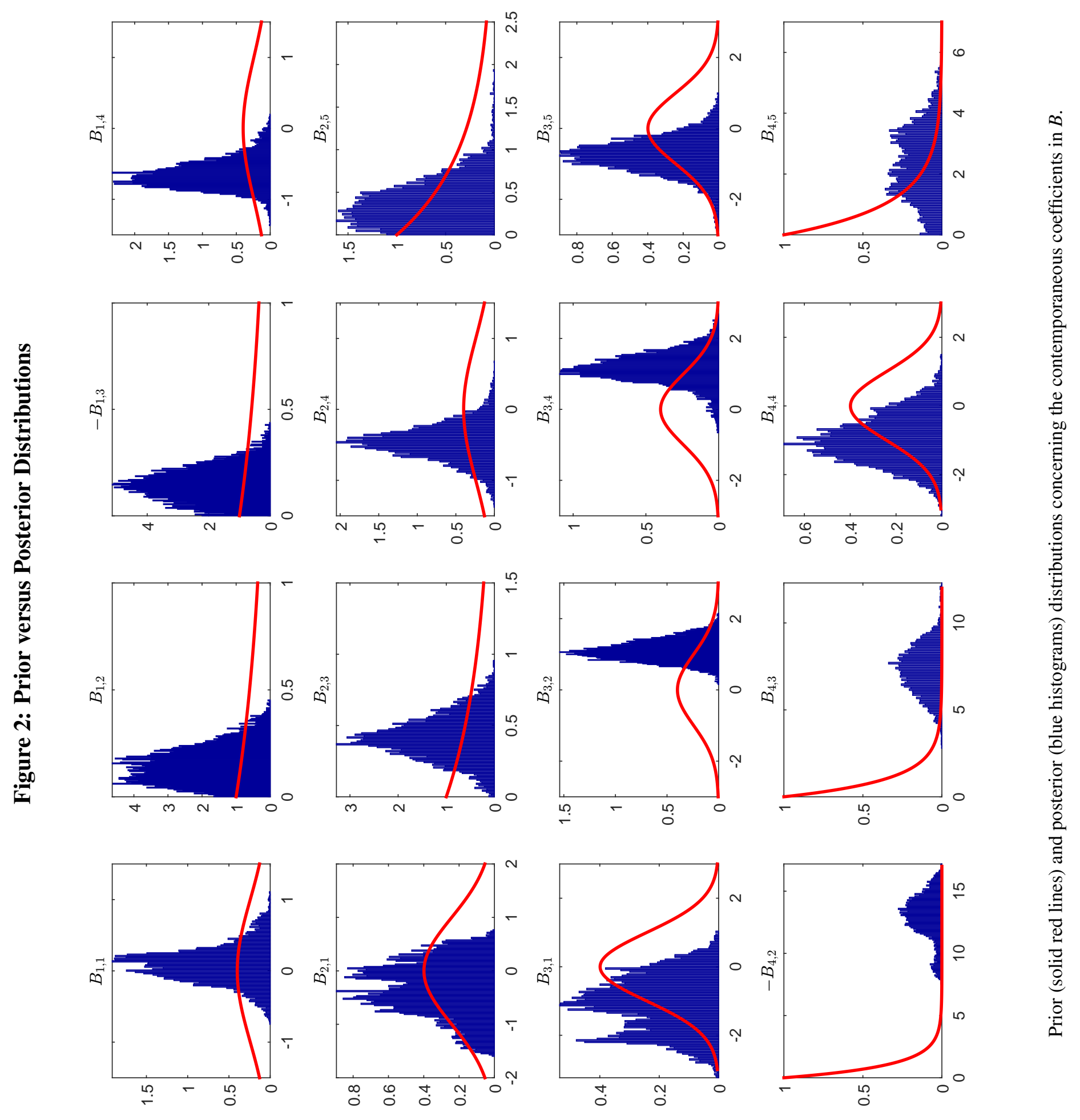


which declines below zero for several periods.

With regard to the implications of the speculative shock, the third row of Figure 3 reports a persistent negative reaction of global output, which remains statistically significant for about 5 years. The global output declines following a reversed hump-shaped trajectory attaining its lowest value of -0.26 percent after eight quarters. The results confirm a significant positive reaction of oil production to the speculative shock as opposed to those reported by Kilian and Murphy (2014), who fail to produce the intuitive positive conditional correlation (at any horizon) even with the same identification restriction. ${ }^{8}$ Further, the short-term reaction of oil prices to a speculative shock shows a similar pattern as a negative permanent supply shock pointing to the important role of speculative innovations in explaining the dynamics of oil prices.

On the demand side induced by the global activity, shocks imply a moderate and not significant positive change in oil prices, which quickly revert to their initial average rate. A permanent disruption to global revenue causes inventories to increase on impact by almost 0.7 percent. The negative and persistent response of oil production may appear puzzling and in contrast with the expected outcome of a global oil demand shock. We would argue that this result is a novel empirical finding as our analysis is the first in the literature that explicitly distinguishes between transitory and permanent shocks to real global output. It seems that when an adverse shock on demand stems from the permanent component, in the agent's interpretation, this corresponds to a persistent innovation that lowers the dependency on oil. This reflects in a moderate decline in the oil production and a build up in the inventories while oil prices remain virtually stable. Surely, this result should be further investigated .

We would argue that the rationale behind the decline in oil availability following a permanent shock on global activity is twofold. One possible explanation may be that innovations and the adoption of alternative sources of energy are embedded in the permanent component of the global activity. An alternative explanation would be the decline in the share of oil-dependent economic activities - i.e., the industrial sector — which should also be reflected in the trend component of global activity. To identify the mechanism underlying the drop in the oil production, we contrast the transmission of a permanent demand shock by assuming the industrial production as a measure of global oil demand, as proposed in Hamilton (2018) and Baumeister and Hamilton (2018), in Section 5.

\footnotetext{
${ }^{8}$ As a reminder, we obtain this result by only constraining the sign of the contemporaneous reactions of the endogenous variables, which is not very restrictive as the standard approach in the literature outlined in Uhlig (2005) allows restricting the implied impulse-response functions for several horizons.
} 


\section{Figure 3: Impulse-Response Functions}
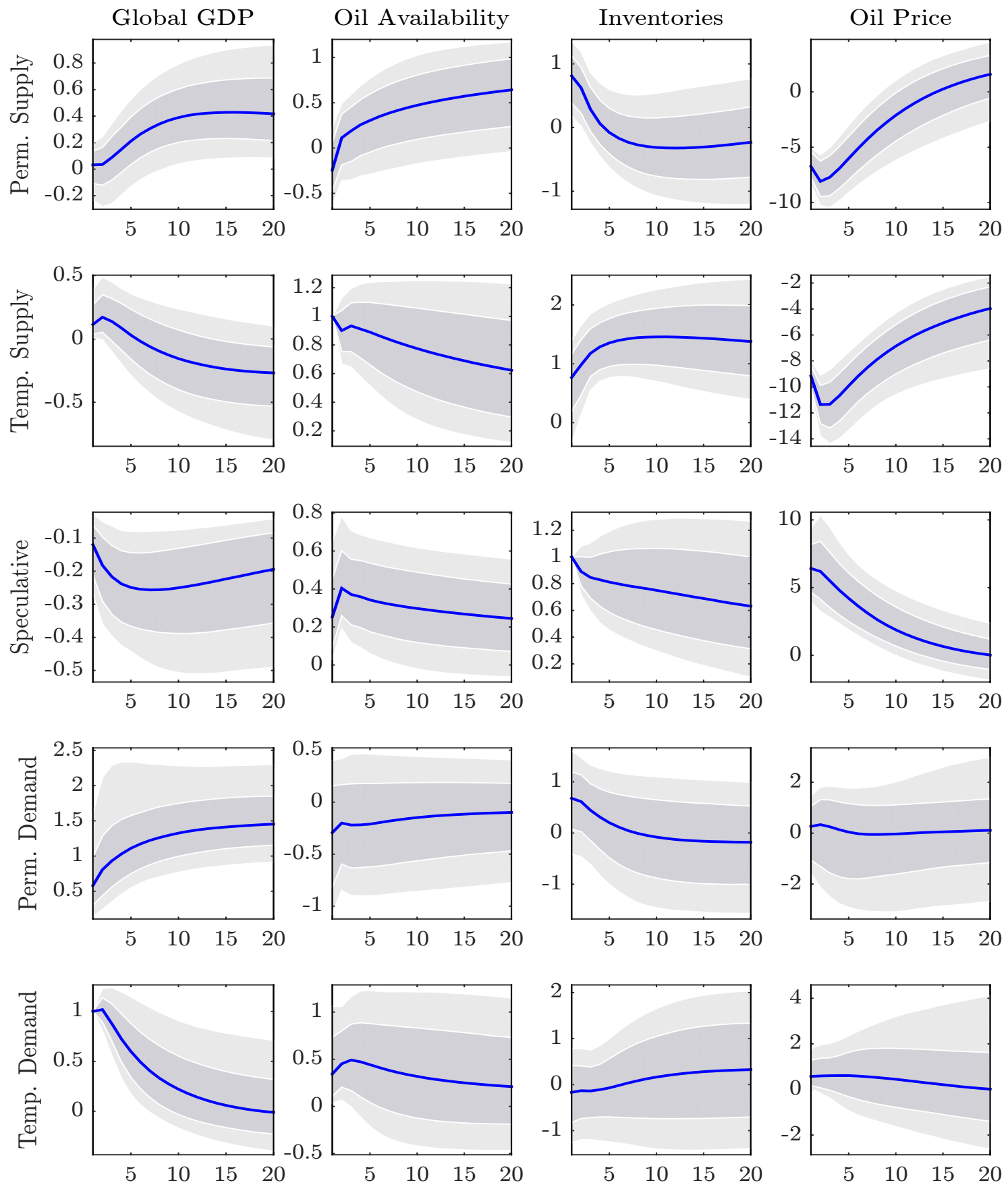

Blue solid lines correspond to the posterior median impulse responses. The dark (light) gray shaded area represents the 68 (90) percent (point-wise) confidence bands for the IRFs. 


\subsection{Variance decomposition}

We analyze the contribution of the different structural shocks to fluctuations in the real global activity, oil production, inventories, and real prices by performing a variance decomposition analysis at different horizons. The top rows of Table 2 present the variance decomposition at the short-term. It is shown that transitory shocks to oil demand are the most important driving force of global activity fluctuations - more than twice the permanent shock - while the oil market innovations yield about 14 percent of the variable dynamics. The oil production variability is mainly explained by unanticipated transitory supply shocks. However, shocks to global activities only explain about 14 percent of the oil production dynamics in the short run and remains virtually unchanged in the long run, which almost equivalent to the contribution of the speculative innovations.

A large fraction of the short-run volatility of oil inventories is tributary to speculative shocks with a declining share over the horizon reaching 40 percent in the long-run. Finally, the three most important drivers of oil prices are the permanent and the transitory oil-supply shocks in addition to the speculative shocks, with the latter explaining between 32 and 34 percent of the volatility over the different horizons. The permanent and transitory oil-supply shocks together account for about two-thirds of the oil price fluctuations both in the short- and long-term horizons, in line with the recent contribution of Lippi and Nobili (2012) who find evidence in favor of the importance of the global (temporary) oil supply shocks in generating the fluctuations of real oil prices (between 40 and 60 percent depending on the horizon). ${ }^{9}$

It is useful to compare our results to those of Kilian and Murphy (2014) who emphasize the importance of the speculative shock of a main driver of oil price fluctuations. Indeed, our results on the role of the speculative shock are comparable; however, the supply-side-driven oil price dynamics in our setup are significantly more important. To us, oil supply shocks offer a more appealing explanation of price fluctuations than global activity innovations and the justification is twofold. First, Kilian and Murphy (2014) adopt a particular measure of global activity that seems to mimic movements in industrial activities while global GDP used in our approach captures other sectors that are in principle less dependent on oil (i.e., services). Second, while the forecast error variance decomposition showcase the role of demand shocks, the authors repetitively refer to supply shocks in the analysis of the historical episodes characterized with oil price large swings.

The direct link between permanent shocks and the endogenous variables is defined according to the results of cointegration tests. Assuming that the implicit trend in oil prices is only driven

\footnotetext{
${ }^{9}$ The authors propose a model where the interplay between the oil market, the global economy and the US economy is managed within a unified framework.
} 
Table 2: Variance Decomposition

\begin{tabular}{|c|c|c|c|c|c|c|}
\hline Horizon & Variable & $\Delta \Psi_{t}^{s}$ & $\phi_{t}^{s}$ & $\phi_{t}^{s p}$ & $\Delta \Psi_{t}^{d}$ & $\phi_{t}^{d}$ \\
\hline \multirow[t]{4}{*}{1} & Global activity & $\begin{array}{c}2.89 \\
{[0.13,5.70]}\end{array}$ & $\begin{array}{c}4.98 \\
{[0.27,10.27]}\end{array}$ & $\begin{array}{c}5.79 \\
{[1.00,10.41]}\end{array}$ & $\begin{array}{l}26.27 \\
{[7.32,45.48]}\end{array}$ & $\begin{array}{c}60.07 \\
{[40.61,78.38]}\end{array}$ \\
\hline & Oil availability & $\begin{array}{c}10.83 \\
{[0.68,22.93]}\end{array}$ & $\begin{array}{c}62.46 \\
{[47.62,76.46]}\end{array}$ & $\begin{array}{c}12.73 \\
{[1.23,26.26]}\end{array}$ & $\begin{array}{c}9.16 \\
{[0.23,22.73]}\end{array}$ & $\begin{array}{c}4.82 \\
{[0.24,9.78]}\end{array}$ \\
\hline & Inventories & $\begin{array}{l}24.22 \\
{[7.18,41.79]}\end{array}$ & $\begin{array}{l}16.85 \\
{[2.12,31.55]}\end{array}$ & $\begin{array}{c}47.13 \\
{[34.71,59.93]}\end{array}$ & $\begin{array}{c}8.89 \\
{[0.62,19.48]}\end{array}$ & $\begin{array}{c}2.91 \\
{[0.14,5.99]}\end{array}$ \\
\hline & Oil prices & $\begin{array}{c}28.37 \\
{[16.48,40.93]}\end{array}$ & $\begin{array}{c}37.28 \\
{[27.22,47.79]}\end{array}$ & $\begin{array}{c}34.02 \\
{[24.02,45.76]}\end{array}$ & $\begin{array}{c}0.20 \\
{[0.01,0.44]}\end{array}$ & $\begin{array}{c}0.12 \\
{[0.00,0.22]}\end{array}$ \\
\hline \multirow[t]{4}{*}{4} & Global activity & $\begin{array}{c}6.23 \\
{[2.17,10.25]}\end{array}$ & $\begin{array}{c}6.83 \\
{[1.94,11.54]}\end{array}$ & $\begin{array}{c}7.09 \\
{[2.54,11.83]}\end{array}$ & $\begin{array}{c}27.89 \\
{[12.92,44.08]}\end{array}$ & $\begin{array}{c}51.96 \\
{[35.82,66.63]}\end{array}$ \\
\hline & Oil availability & $\begin{array}{c}18.49 \\
{[6.86,30.61]}\end{array}$ & $\begin{array}{c}52.81 \\
{[42.12,62.36]}\end{array}$ & $\begin{array}{c}14.24 \\
{[4.85,25.28]}\end{array}$ & $\begin{array}{c}9.10 \\
{[0.61,22.53]}\end{array}$ & $\begin{array}{c}5.36 \\
{[1.11,9.44]}\end{array}$ \\
\hline & Inventories & $\begin{array}{c}26.83 \\
{[13.39,40.87]}\end{array}$ & $\begin{array}{l}19.16 \\
{[8.36,30.53]}\end{array}$ & $\begin{array}{c}40.87 \\
{[29.89,53.01]}\end{array}$ & $\begin{array}{c}9.59 \\
{[1.08,19.75]}\end{array}$ & $\begin{array}{c}3.55 \\
{[0.69,6.69]}\end{array}$ \\
\hline & Oil prices & $\begin{array}{c}28.73 \\
{[16.64,41.54]}\end{array}$ & $\begin{array}{c}37.67 \\
{[27.11,48.40]}\end{array}$ & $\begin{array}{c}33.21 \\
{[23.57,44.69]}\end{array}$ & $\begin{array}{c}0.24 \\
{[0.03,0.47]}\end{array}$ & $\begin{array}{c}0.16 \\
{[0.02,0.27]}\end{array}$ \\
\hline \multirow[t]{4}{*}{12} & Global activity & $\begin{array}{c}7.58 \\
{[3.15,11.86]}\end{array}$ & $\begin{array}{c}7.52 \\
{[2.43,12.41]}\end{array}$ & $\begin{array}{c}6.92 \\
{[2.60,11.42]}\end{array}$ & $\begin{array}{c}27.61 \\
{[13.94,42.64]}\end{array}$ & $\begin{array}{c}50.37 \\
{[34.83,64.23]}\end{array}$ \\
\hline & Oil availability & $\begin{array}{c}18.85 \\
{[7.16,31.01]}\end{array}$ & $\begin{array}{c}52.43 \\
{[41.99,61.81]}\end{array}$ & $\begin{array}{c}14.21 \\
{[4.88,25.22]}\end{array}$ & $\begin{array}{c}9.08 \\
{[0.64,22.43]}\end{array}$ & $\begin{array}{c}5.43 \\
{[1.17,9.54]}\end{array}$ \\
\hline & Inventories & $\begin{array}{c}27.14 \\
{[13.81,40.89]}\end{array}$ & $\begin{array}{l}19.09 \\
{[8.55,30.09]}\end{array}$ & $\begin{array}{c}40.17 \\
{[29.30,52.45]}\end{array}$ & $\begin{array}{c}9.78 \\
{[1.15,19.93]}\end{array}$ & $\begin{array}{c}3.83 \\
{[0.86,7.07]}\end{array}$ \\
\hline & Oil prices & $\begin{array}{c}29.41 \\
{[17.27,42.37]}\end{array}$ & $\begin{array}{c}37.25 \\
{[26.70,48.01]}\end{array}$ & $\begin{array}{c}32.92 \\
{[23.23,44.45]}\end{array}$ & $\begin{array}{c}0.25 \\
{[0.04,0.48]}\end{array}$ & $\begin{array}{c}0.17 \\
{[0.03,0.30]}\end{array}$ \\
\hline \multirow[t]{4}{*}{$\infty$} & Global activity & $\begin{array}{c}8.04 \\
{[3.46,12.57]}\end{array}$ & $\begin{array}{c}7.81 \\
{[2.74,12.69]}\end{array}$ & $\begin{array}{c}7.03 \\
{[2.69,11.55]}\end{array}$ & $\begin{array}{c}27.42 \\
{[14.16,42.13]}\end{array}$ & $\begin{array}{c}49.70 \\
{[34.45,63.42]}\end{array}$ \\
\hline & Oil availability & $\begin{array}{l}19.16 \\
{[7.61,31.26]}\end{array}$ & $\begin{array}{c}52.18 \\
{[41.84,61.59]}\end{array}$ & $\begin{array}{c}14.18 \\
{[4.89,25.13]}\end{array}$ & $\begin{array}{c}9.03 \\
{[0.65,22.26]}\end{array}$ & $\begin{array}{c}5.44 \\
{[1.18,9.53]}\end{array}$ \\
\hline & Inventories & $\begin{array}{c}27.30 \\
{[14.13,40.84]}\end{array}$ & $\begin{array}{c}19.14 \\
{[8.66,30.01]}\end{array}$ & $\begin{array}{c}39.89 \\
{[29.18,52.03]}\end{array}$ & $\begin{array}{c}9.77 \\
{[1.17,19.89]}\end{array}$ & $\begin{array}{c}3.91 \\
{[0.92,7.13]}\end{array}$ \\
\hline & Oil prices & $\begin{array}{c}29.82 \\
{[17.64,42.90]}\end{array}$ & $\begin{array}{c}37.04 \\
{[26.37,47.79]}\end{array}$ & $\begin{array}{c}32.68 \\
{[23.00,44.19]}\end{array}$ & $\begin{array}{c}0.27 \\
{[0.04,0.51]}\end{array}$ & $\begin{array}{c}0.20 \\
{[0.04,0.34]}\end{array}$ \\
\hline
\end{tabular}

by permanent oil supply shocks does not preclude per se the influence of demand shocks on the dynamics of prices. The same applies to inventories and oil production. Although, the result showing the weak correlation between oil prices and permanent shocks on global activity may seem surprising, we would argue that it is not driven only by the cointegration assumptions. As a robustness check, we assume that the trend in oil prices and inventories could also be explained by 
the permanent component of global demand. Formally, we change Equation (1) as follows

$$
\left[\begin{array}{c}
\hat{x}_{t} \\
\hat{z}_{t} \\
\hat{i}_{t} \\
\hat{p}_{t}
\end{array}\right] \equiv\left[\begin{array}{c}
x_{t}-\Psi_{t}^{d} \\
z_{t}-\Psi_{t}^{s} \\
i_{t}-\Psi_{t}^{s}-\eta_{i} \Psi_{t}^{d} \\
p_{t}-\Psi_{t}^{s}-\eta_{p} \Psi_{t}^{d}
\end{array}\right]
$$

Assuming $\eta_{i}=\eta_{p}=1$ mildly increases the contribution of permanent demand shocks in the long-term volatility of oil prices-about 1 percent. However, once we include $\eta_{i}$ and $\eta_{p}$ in the set of estimated parameters, we find posterior averages of -1.34 and 3.01, respectively. Given the higher coefficient of permanent demand shocks, the share of oil price volatility explained by those innovations increases to about 9 percent, which is still modest. ${ }^{10}$

\subsection{Conditional correlations}

Table 3 presents estimates of both unconditional and conditional correlations between the endogenous variables of our benchmark empirical model. Although one can have a broadly clear idea about the sign of the conditional cross-correlations through the impulse-response functions, it is important to complement the aforementioned relations with the evaluation of a numerical evaluation of the co-movement between some key variables.

The first line of Table 3 shows a weak unconditional correlation between the growth rates of global GDP and oil production. This result is mainly driven by the negative conditional comovement following permanent demand innovations, which explain about 27 percent and 10 percent of the volatitilities of global GDP and oil production, respectively. Note that a speculative shock also yields a negative correlation between the two variables; however, the variance decomposition exercise reveals a relatively weak role of this shock in explaining the short- and long-term dynamics of global GDP and oil production. We argue that this is a novel finding in our analysis. In fact, the global activities defined by Kilian and Murphy (2014) and Baumeister and Hamilton (2018) also exhibit a low correlation with the oil production; however, the only shock that yields a negative correlation between the two variables is the speculative shock, which amplifies its contribution in the variance decomposition. Besides, it is hard to read the magnitude of the conditional correlations from the impulse-response functions reported in the two papers as they frequently exhibit sign changes and erratic trajectories.

\footnotetext{
${ }^{10}$ We assume a uniform prior distribution of mean 0 and standard deviation 1 for the two parameters.
} 
Table 3: Conditional Correlations

\begin{tabular}{|c|c|c|c|c|c|c|c|}
\hline \multirow[t]{2}{*}{ Correlation } & \multirow[t]{2}{*}{ Observed } & \multirow{2}{*}{$\begin{array}{c}\text { Unconditional } \\
\text { correlation }\end{array}$} & \multicolumn{5}{|c|}{ Conditional correlation } \\
\hline & & & $\Delta \Psi_{t}^{s}$ & $\phi_{t}^{s}$ & $\phi_{t}^{s p}$ & $\Delta \Psi_{t}^{d}$ & $\phi_{t}^{d}$ \\
\hline $\operatorname{Corr}\left(\Delta x_{t}, \Delta z_{t}\right)$ & 0.13 & $\begin{array}{c}0.12 \\
{[0.04,0.20]}\end{array}$ & $\begin{array}{c}0.10 \\
{[-0.37,0.54]}\end{array}$ & $\begin{array}{c}0.56 \\
{[0.22,0.82]}\end{array}$ & $\begin{array}{c}-0.71 \\
{[-0.91,-0.37]}\end{array}$ & $\begin{array}{l}-0.54 \\
{[-0.83,0.57]}\end{array}$ & $\begin{array}{c}0.79 \\
{[0.38,0.95]}\end{array}$ \\
\hline $\operatorname{Corr}\left(\Delta x_{t}, \Delta i_{t}\right)$ & -0.12 & $\begin{array}{c}-0.10 \\
{[-0.19,-0.02]}\end{array}$ & $\begin{array}{l}-0.27 \\
{[-0.76,0.28]}\end{array}$ & $\begin{array}{c}0.30 \\
{[-0.23,0.70]}\end{array}$ & $\begin{array}{c}-0.73 \\
{[-0.91,-0.43]}\end{array}$ & $\begin{array}{c}0.52 \\
{[-0.14,0.88]}\end{array}$ & $\begin{array}{c}-0.51 \\
{[-0.94,0.67]}\end{array}$ \\
\hline $\operatorname{Corr}\left(\Delta x_{t}, \Delta p_{t}\right)$ & -0.15 & $\begin{array}{c}-0.17 \\
{[-0.24,-0.10]}\end{array}$ & $\begin{array}{c}0.02 \\
{[-0.47,0.65]}\end{array}$ & $\begin{array}{c}-0.71 \\
{[-0.90,-0.34]}\end{array}$ & $\begin{array}{c}-0.70 \\
{[-0.91,-0.37]}\end{array}$ & $\begin{array}{c}0.37 \\
{[-0.74,0.87]}\end{array}$ & $\begin{array}{c}0.70 \\
{[0.23,0.94]}\end{array}$ \\
\hline $\operatorname{Corr}\left(\Delta z_{t}, \Delta i_{t}\right)$ & 0.18 & $\begin{array}{c}0.21 \\
{[0.13,0.28]}\end{array}$ & $\begin{array}{l}-0.57 \\
{[-0.82,0.10]}\end{array}$ & $\begin{array}{c}0.86 \\
{[0.19,0.97]}\end{array}$ & $\begin{array}{c}0.78 \\
{[0.29,0.94]}\end{array}$ & $\begin{array}{l}-0.58 \\
{[-0.86,0.72]}\end{array}$ & $\begin{array}{c}-0.17 \\
{[-0.81,0.64]}\end{array}$ \\
\hline $\operatorname{Corr}\left(\Delta z_{t}, \Delta p_{t}\right)$ & -0.18 & $\begin{array}{c}-0.18 \\
{[-0.24,-0.11]}\end{array}$ & $\begin{array}{c}0.46 \\
{[-0.27,0.75]}\end{array}$ & $\begin{array}{c}-0.93 \\
{[-0.97,-0.87]}\end{array}$ & $\begin{array}{c}0.82 \\
{[0.36,0.95]}\end{array}$ & $\begin{array}{c}-0.43 \\
{[-0.87,0.61]}\end{array}$ & $\begin{array}{c}0.45 \\
{[-0.010 .81]}\end{array}$ \\
\hline $\operatorname{Corr}\left(\Delta i_{t}, \Delta p_{t}\right)$ & -0.09 & $\begin{array}{c}-0.07 \\
{[-0.15,0.00]}\end{array}$ & $\begin{array}{c}-0.81 \\
{[-0.89,-0.66]}\end{array}$ & $\begin{array}{c}-0.88 \\
{[-0.96,-0.34]}\end{array}$ & $\begin{array}{c}0.96 \\
{[0.92,0.99]}\end{array}$ & $\begin{array}{c}0.03 \\
{[-0.85,0.81]}\end{array}$ & $\begin{array}{l}-0.23 \\
{[-0.76,0.49]}\end{array}$ \\
\hline
\end{tabular}

Notes: The observed correlations are computed directly from the data whereas the unconditional and conditional correlations estimates are based upon the benchmark empirical model where we iteratively assume that each of the five structural shocks is the only shock hitting the economy. Numbers in square brackets represent the 16 and $86^{\text {th }}$ percentile Hall confidence bands.

\subsection{Historical decomposition of oil prices}

In this section we provide a structural interpretation for historical episodes characterized by major oil price changes, and compare our findings with previous studies. Figure 4 presents the evolution of the real oil prices along with key oil market events in the period 1974 to 2018 . One can notice that until the late 1980s the speculative shocks contributed to a considerable share of the large swings of oil prices; then, their impact significantly declined during the subsequent decades. Besides, transitory and permanent innovations on the supply side played an important role in most episodes, although with different magnitudes and persistence. To distinguish between the transitory and permanent shocks we remind the reader that following the impulse-response exercise two main results emerged, which will guide us in the discussion below. Namely, The oil production and inventories' reactions show different persistence depending on the shock as well as the sign of the global activity trajectory in the medium term - positive (negative) in the case of persistent (transitory) supply shock.

Adopting a novel narrative sign restriction approach, Antolín-Díaz and Rubio-Ramírez (2018) 
introduce the conjecture that "the oil supply shock must take negative values in December 1978, January 1979 (outbreak of the Iranian Revolution), in September and October 1980 (outbreak of the Iran-Iraq War), August 1990 (outbreak of the Persian Gulf War), December 2002 (Venezuela oil strike), March 2003 (outbreak of the Iraq War) and February 2011 (outbreak of the Libyan Civil War)”. These assumptions are commonly acknowledged in the literature (see for instance Kilian, 2008; Hamilton, 2009) and should correspond to a challenge to our benchmark model as our identification restriction do not systematically imply such results per se. Furthermore, our model is suitable to take this challenge to another dimension through allocating the sources of the shocks to permanent versus transitory components in addition to speculation. The next paragraphs detail the main drivers of several historical episodes of interest obtained with our benchmark identification scheme.

Iranian revolution (1978). Kilian and Murphy (2014) argue in favor of the demand side shocks as well as speculative shocks as the main triggers for the upsurge in oil prices following the Iranian revolution, despite the shortage in oil production that took effect in 1978 and 1979. The reason is that much of the observed increase in the real price of oil only occurred later in 1979 after Iranian oil production had resumed. ${ }^{11}$ We report similar results in terms of the importance of speculative shocks in generating a share of the oil price increase; nonetheless, we find that this shock yielded the price increase towards the end of the episode. In fact, speculative shocks dampened international prices at the outbreak of the Iranian revolution. We also find that permanent supply shocks are responsible for the bulk of price volatility in that period. ${ }^{12}$ To reconcile this result with the fact that prices remained high while the oil production resumed, we refer to the simultaneous impact of the transitory supply shock, which we interpret as an OPEC decision to compensate for the shortage in oil availability. ${ }^{13}$ Now, looking carefully at the global activity during that period real GDP growth started declining in 1978 hitting the negative territory starting from 1979Q2 and subsequently remained below zero until the end of 1980, which dismisses the assertion that demand

\footnotetext{
${ }^{11}$ Before the revolution, Iran was producing an average of just over 5.5 million barrels a day (mbd). The peak was reached in September 1978 when production rose to 6 mbd. Thus Iran's oil production came down 5.5 mbd in October 1978, $3.4 \mathrm{mbd}$ in November, and $2.4 \mathrm{mbd}$ in December

${ }^{12}$ Though the revolutionary Iranian government resumed its oil production fairly quickly and set 4 mbd as its new production targets, which reinforces the argument in favor of a permanent interpretation of the initial shock.

${ }^{13}$ Historical evidence shows that Saudi Arabia was in a comfortable position to increase its oil production from $6 \mathrm{mbd}$ to more than $10.5 \mathrm{mbd}$. More generally, Alkhathlan et al. (2014) report that the Saudi output is found to be negatively correlated and highly volatile in comparison to that of other OPEC producers; and Saudi Arabia has the unique ability to act as a swing producer, filling the gap at times of oil disruptions.
} 
shocks as a major source of oil price fluctuations during that period.

The Collapse of OPEC in 1986. In 1986 Saudi Arabia decided to discontinue playing the role of a swing producer as the Kingdom boosted production to $5 \mathrm{mbd}$ and prices immediately collapsed — falling 50 percent from 1985 to 1986. Although the source of this shock is an obvious supply driven one, the question whether it is permanent, transitory or a combination of both remains unanswered. In response to this question, our model suggests that positive transitory and demand shocks occurred at the same time while the former contributed slightly more to the collapse of prices. In contrast, the speculative shock remained virtually muted during that episode as opposed to Kilian and Murphy (2014) who find a drop in speculative demand reinforced the decline in the real price of oil. Notwithstanding, when we carefully look at the inventories time series, the registered change in the first three quarters of 1986 is positive then turns mildly negative towards the end of the year.

The Gulf War in 1990. The Gulf War in August 1990 represents the largest exogenous event encompassing the concurrent cutbacks in production in Iraq, Kuwait and the United Arab Emirates. This shock to supply was almost totally perceived as a transitory one as permanent shocks to the oil market trend barely affected prices at that period. Besides, speculative innovations moderately affected prices but heavily contributed to their decline in the subsequent periods where oil inventories registered several periods of negative growth until the end of 1993. Surprisingly, other papers attribute equivalent shares of price decline to demand and supply shocks (see for instance Caldara et al., 2018).

The Venezuelan Crisis and Iraq War of 2002-03. The Venezuelan crisis and Iraq War resulted in an approximately 13 percent upsurge in the price of crude oil. The decomposition of price dynamics captures an episode of sharp temporary decline in oil supply — consistent with the narrative analysis - accounting for about the total price upswing. Subsequently, speculative innovations eventually became prominent drivers of price softening following a sequence of negative shocks. In parallel, permanent shocks to supply trend remained muted.

The Global Financial Crisis of 2008. The model attributes the bulk of the decline in the price of oil to negative oil-specific permanent supply shocks most likely owing to the simultaneous decline in oil production and the relatively small movements in measures of global activity. One can notice that global activity shocks played a minor role in this episode as quarterly real growth rates remained positive in 2008 and 2009 except at the third quarter of the first year of the crisis. 


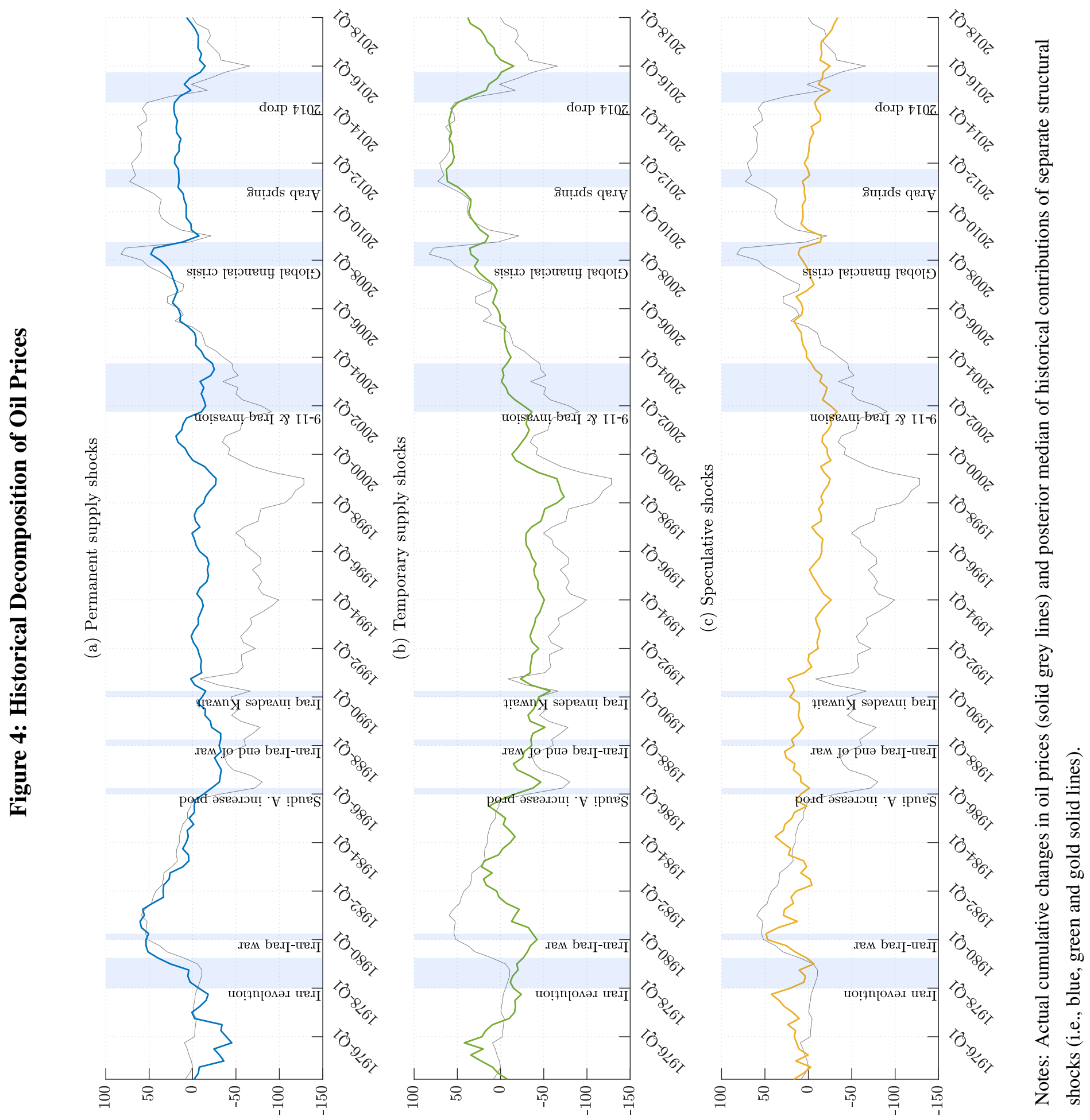


Negative shocks on inventories and on transitory supply shocks equally contributed to the price dip; and once combined their impact has almost at a same magnitude of the permanent supply shock.

The Oil Price Plunge of 2014. Oil prices have declined sharply starting from 2014Q2 and remained at historically low levels for more than two years amid a large increase in oil production and inventories. ${ }^{14}$ The accumulation of oil stocks along with the decline in prices rule out the possibility of having the speculative shocks as a contributor to this episode. A registered pickup in production growth combined with virtually stable real activity growth suggests that supply factors explain most of the decline in oil prices since mid-2014. Further, several oil markets experts recently reported, that the oil "break-even" price declined by roughly 50 per cent between 2013 and 2016, which also reinforce the premise that oil market specific shocks are the main drivers of the recent price plunge. ${ }^{15}$

\section{Iterative Estimation}

A simple approach to gauging the change of the empirical results over time is to estimate the empirical model over different samples. In particular, we run the estimation on rolling-windows of data with fixed length - 120 observations — starting from 1974Q1 and repeating the estimation moving ahead the starting date by one year. ${ }^{16}$ In the following we highlight the main results that are dependent on the considered samples with statistically significant changes over time; namely, the oil prices responses to speculative shocks.

\subsection{Variance decomposition}

Figure 5 shows the contributions of the five structural shocks to the forecast error variance decomposition of real oil prices based on the ten-year rolling window estimation results. In the early samples, speculative innovations explain the bulk of oil price volatility with a contribution remaining

\footnotetext{
${ }^{14}$ Brent prices, for example, fell from an average of USD 110 per barrel between January 2011 and June 2014 to a low of USD 31 in January 2016

${ }^{15}$ Prest (2018) attribute crude oil price drop to demand shocks; however, the author approximates supply shocks through the U.S. shale revolution. We would argue that these are not the only source of supply shocks and our definition of these innovations are more general.

${ }^{16}$ Here, considering quarterly data for 30 years is assumed delivering reliable estimation results. Extending the number of observations per window to 160 delivered very similar results.
} 
above 50 percent until the sample 1979Q1-2008Q4; then declines in the following time windows. This result is consistent with the outcome of the oil price historical decomposition showing a decline in the fluctuations of prices yielded by speculative innovations as described in the bottom row of Figure 4. In parallel, oil supply shocks (permanent and transitory) became dominant in the most recent samples explaining about 80 percent of the overall volatility, which could result from either the increase of their standard deviations, the change in the elasticity of prices with respect to oil production, or both. Interestingly, innovations to the permanent component of oil supply became more important in explaining the oil price fluctuation - from virtually 0 in the early samples to more than 60 percent more recently.

\section{Figure 5: Change in the Variance Decomposition of Oil Prices}

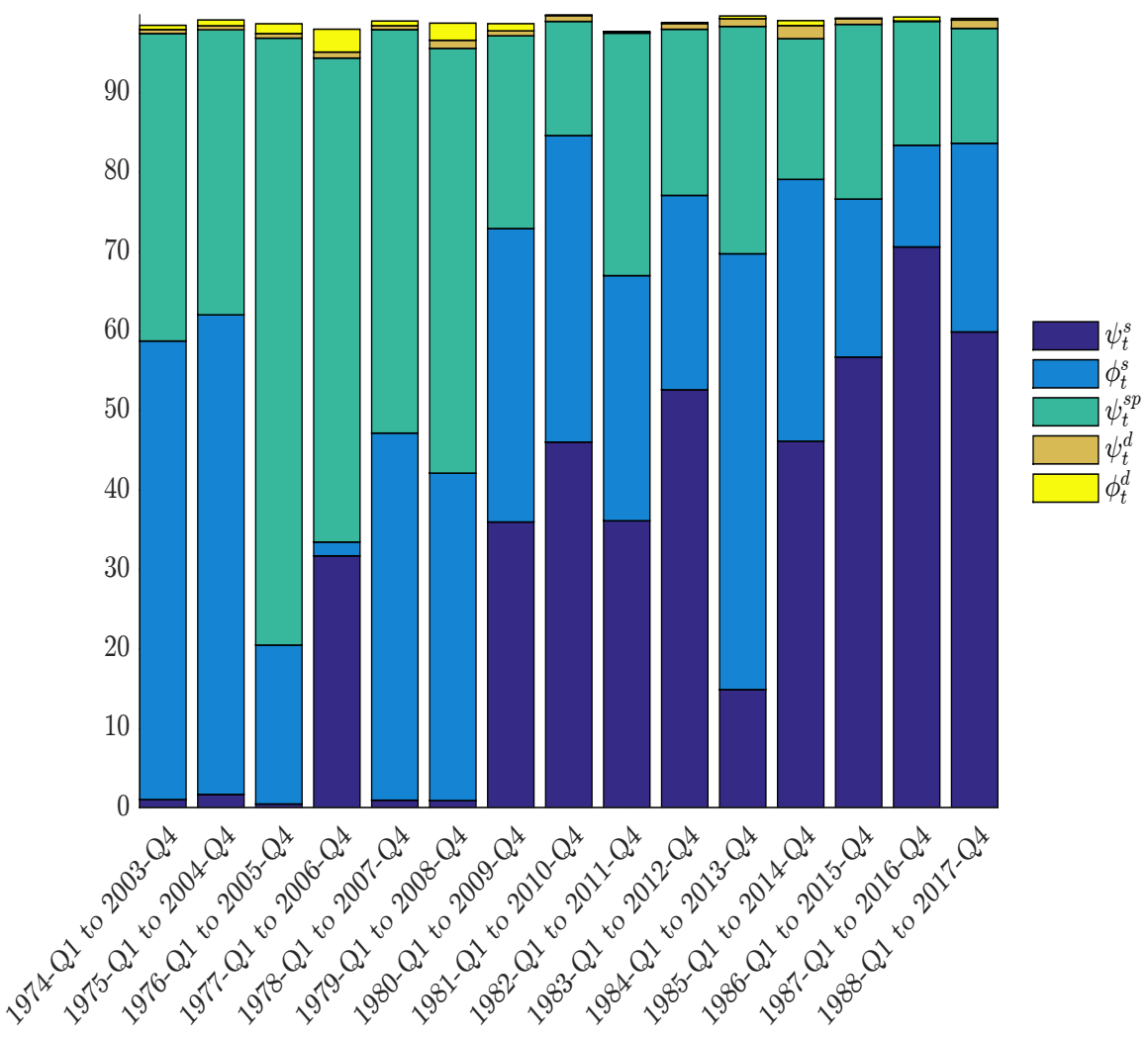

We present the behavior of the standard deviation parameter estimates over the expanding estimation window in Figure 6, where the solid black lines report the posterior means while the grey areas are the 90 percent confidence intervals. The posterior mean of the permanent oil market shock do vary considerably as the estimation sample period covers more recent periods and are also more precisely estimated. This result is intimately related to the change in the variance decomposition 
of oil prices, which registered a significant increase over time. In contrast, the posterior standard deviation mean values of the remaining shocks broadly follow the opposite pattern although showing a milder decline. ${ }^{17}$ The volatility of speculative shocks shows a small decline only towards the end of the sample indicating that the propagation mechanisms should be the major contributor of the decline of the share of oil price fluctuations conditional to this shock.

Figure 6: Change in the Standard Deviations
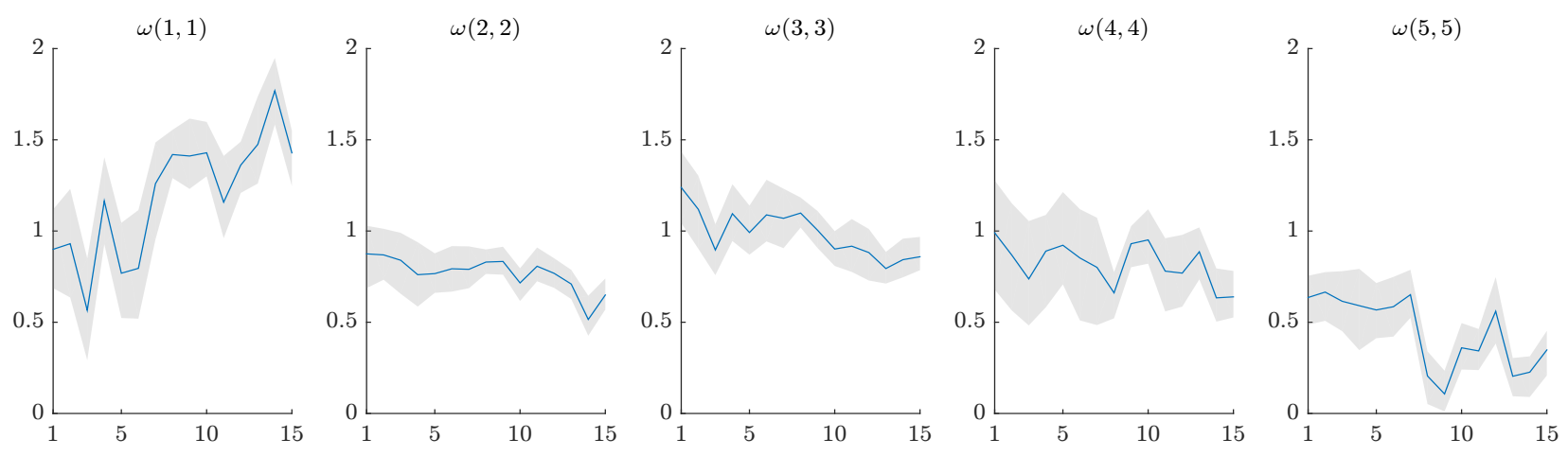

\subsection{Oil price reaction to speculative shocks}

Changes in the variance decomposition summarize some dimensions of the change in the impulse responses to different shocks. Accordingly, the changes experienced over the sample in those contributions of shocks must be reflecting parallel changes in the underlying impulse- response functions. Next, we present and briefly discuss the evolution over time of the oil price reaction that can account for the declining contribution of speculative innovations in the oil market dynamics.

Figure 7 illustrates the decline of the real oil price reaction to an unexpected speculative shock, which alludes to the change in the dynamic parameters of the autoregressive model. The responses are hump shaped in the early samples with a peak reached after two to three quarters. Later the trajectories drastically decline and remain below zero shortly after the impulse. On impact, the oil price response drops from 12 percent to 2 percent in the latest sample (1988Q1-2017Q4). As a conclusion, the decreasing contribution of speculative shocks are principally implied by the change in oil market dynamics since a very little evidence of change in the variance of the shock is depicted by the iterative estimation exercise.

\footnotetext{
${ }^{17} \mathrm{Al}$ Rousan et al. (2018) show some evidence of the declining coordination between OPEC members during the recent periods, which could relate to the fall in the temporary supply shock volatility, $\omega(2,2)$, as OPEC decisions have generally a short-lived impact on oil production and prices.
} 
Figure 7: Change in the Response of Oil Prices to a Speculative Shock

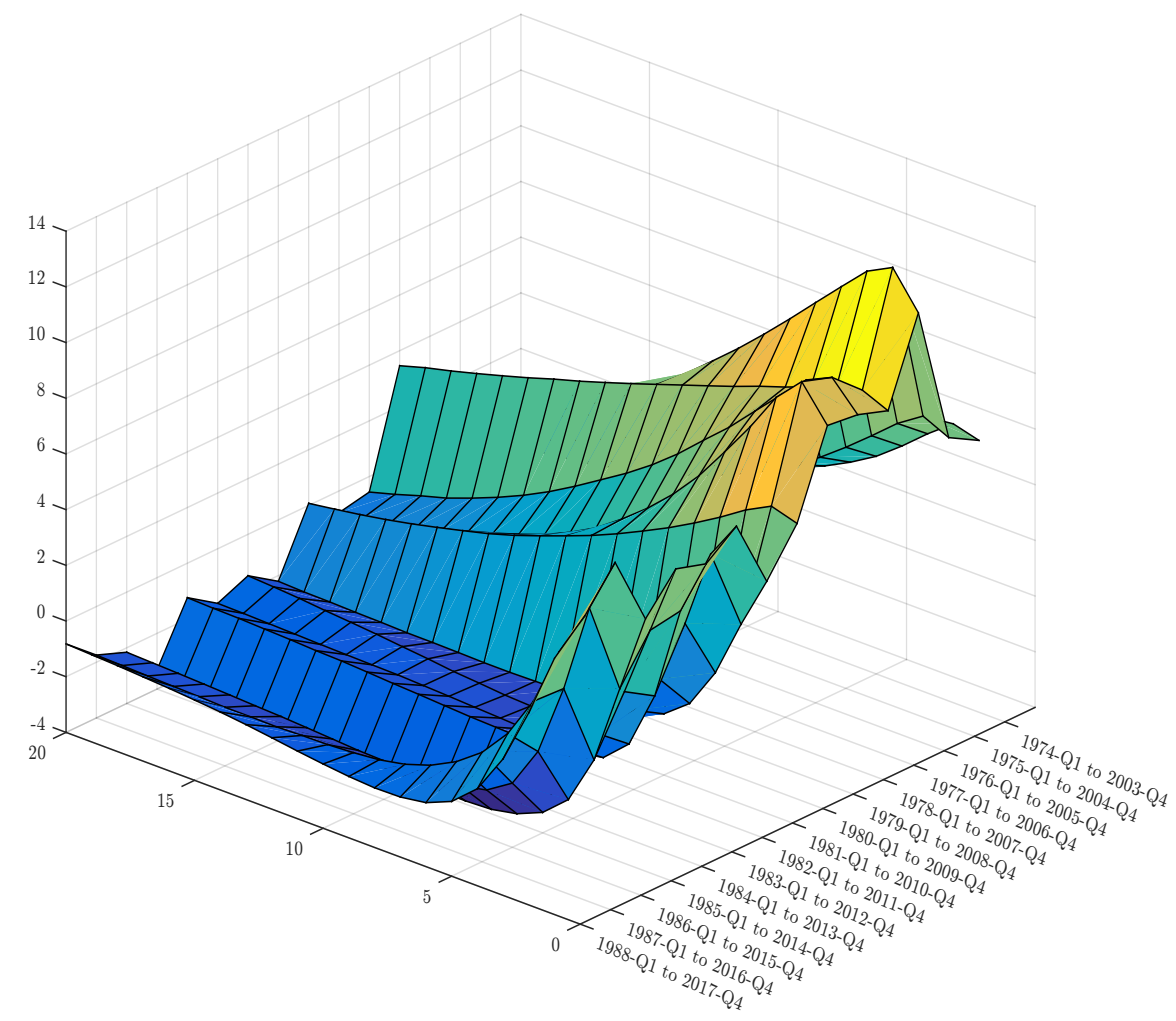

\section{Robustness Check}

As a robustness check, we estimate a variant of our benchmark model using an alternative measure of global activity Baumeister and Hamilton (2018) based on an extended industrial production index in the OECD and 6 major other countries - the same countries (except the Russian Federation) are covered in the global real GDP adopted in our baseline model. This exercise serves two key purposes. Firstly, we compare the empirical results of the model based on alternative measures of global activity. Secondly, this analysis serves to assess whether the negative conditional correlation between global activity and oil production to permanent demand shocks is tributary to technological innovations - less dependence on oil - or to a change in the share of industrial activity in the aggregate output. 


\section{Figure 8: Impulse-Response Functions}
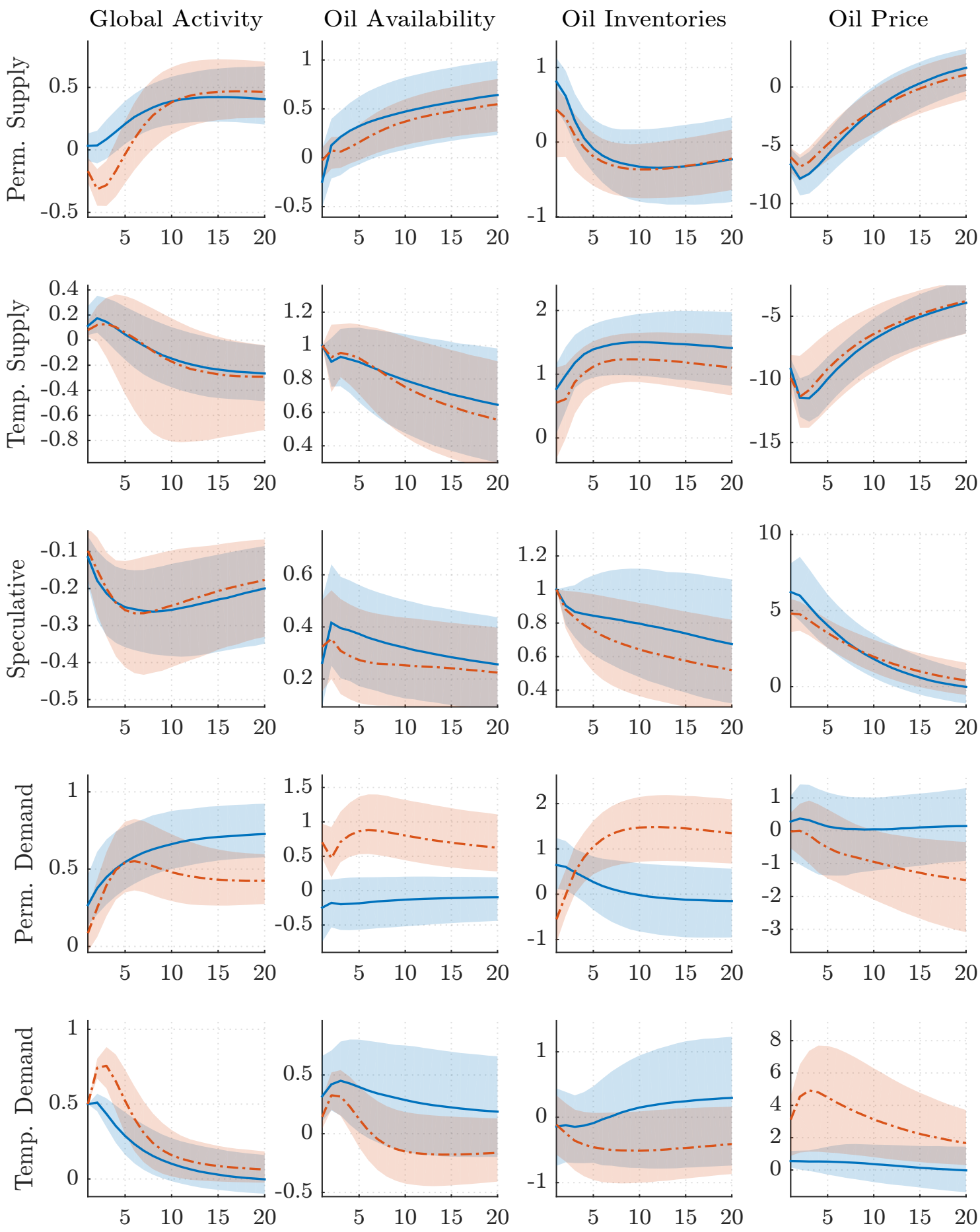

Notes: Blue solid lines correspond to the posterior median impulse responses and dashed blue lines identify the 90 percent confidence intervals. 
Figure 8 plots the median impulse-response functions of the endogenous variables using alternatively the global GDP and the aggregated industrial index. Three features of Figure 8 stand out. First, changing the definition of the global economic activity has little consequences on the outcomes of the transitory shocks, except in the case of the transitory demand shock where the global activity index becomes less responsive. Second, the permanent supply shock has a positive and persistent impact on the global industrial index and the trajectory is significantly different from the benchmark case especially in the short-term horizon. Third, when it comes to the oil production response to a permanent demand shock, the pattern of impact response turns out to be positive as opposed to the benchmark case. The two trajectories are significantly different over the 5-year horizon and beyond. In parallel, inventories decline and remain below zero for several years and oil prices persistently increase.

As discussed earlier, a negative response of oil production to shocks to the trend of the global economic activity can emerge as a result of the continued energy efficiency gains achieved over the past decades in advanced economies, which mitigated the relationship between oil and the real sector (see for instace Blanchard and Galí, 2007). An alternative explanation would be the decline of the share of industrial activities in the total output. Figure 8 reveals that the permanent shocks on global demand tend to capture changes in the share of the industrial sector rather than decreasing dependency on oil in the production as oil production still exhibits a positive persistent response. However, this does not preclude the possibility a less pronounced effect of innovation and energy diversification on the long-term trend of oil production.

\section{Conclusion}

We develop an empirical approach where we distinguish between transitory and permanent shocks in the global economic activity and the oil market. The methodology employs the flexibility of SVAR techniques, the narrative approach to identify structural shocks, and the Kalman filtering to allow to infer the permanent and transitory components of oil demand and supply shocks. The methodology is appealing in several respects. First, the sources contributing to non-stationarity of the variables are explicitly taken into consideration in the empirical framework. Second, it reflects the identified cointegration relations between the endogenous variables. Third, the procedure is simple to use as it relies on standard Bayesian techniques and use the Kalman filter approach to assess the relative importance of the shock components over time.

Empirical results suggest that the supply side of the market has been an important determinant 
of the real price of oil both in terms of the variance decomposition and the prominent episodes of oil fluctuations. In average, the transitory and permanent shocks to oil supply played an equal role; however, shocks on the trend witnessed a growing influence on the oil price volatility over time. Although speculative shocks have exerted significant influence over major oil price swings in the 1970s and 1980s, their effect drastically declined in the most recent years stemming from the the weaker volatility of inventories and a declining price responsiveness to speculative innovations.

One interesting extension worth pursuing is to modify the identification scheme of the oil sector specific shocks through allowing agents to learn about the uncertain nature along with the persistence of the underlying shocks. Accordingly, one would expect that perceptions regarding the persistence of shocks could be important in explaining the contribution of permanent versus transitory shocks to the forecast error variance decomposition of the endogenous variables affecting the global oil market. 


\section{References}

Al Rousan, S., R. Sbia, and B. K. O. Tas (2018). A dynamic network analysis of the world oil market: Analysis of OPEC and non-OPEC members. Energy Economics 75, 28-41.

Alkhathlan, K., D. Gatelyb, and M. Javidc (2014). Analysis of Saudi Arabia's behavior within OPEC and the world oil market. Energy Policy 64, 209-225.

Antolín-Díaz, J. and J. F. Rubio-Ramírez (2018). Narrative sign restrictions for SVARs. American Economic Review 108, 2802-2829.

Baum, C. F. (2004). A review of stata 8.1 and its time series capabilities. International Journal of Forecasting 20, 151-161.

Baumeister, C. J. and J. D. Hamilton (2018). Structural interpretation of vector autoregressions with incomplete identification: Revisiting the role of oil supply and demand shocks. NBER Working Paper No. 24167.

Blanchard, O. J. and J. Galí (2007). The macroeconomic effects of oil price shocks: Why are the 2000s so different from the 1970s? NBER Chapters, in: International Dimensions of Monetary Policy, pages 373-421.

Blanchard, O. J. and J. Galí (2010). The macroeconomic effects of oil price shocks: why are the 200 0s so different from the 1970s? In J. Galí and M. Gertler (Eds.), International Dimensions of Monetary Policy, pp. 373-421. University of Chicago Press.

Caldara, D., M. Cavallo, and M. Iacoviello (2018). Oil price elasticities and oil price fluctuations. Journal of Monetary Economics (forthcoming).

Canova, F. and M. Paustian (2007). Measurement with some theory: Using sign restrictions to evaluate business cycle models. CREI, manuscript.

Cherif, R., F. Hasanov, and A. Pande (2017, May). Riding the energy transition; oil beyond 2040. IMF Working Papers 17/120, International Monetary Fund.

Clemente, J., A. Montañés, and M. Reyes (1998). Testing for a unit root in variables with a double change in the mean. Economics Letters 59, 175-182.

Dickey, D. A. and W. A. Fuller (1979). Distribution of the estimators or autoregressive time series with a unit root. Journal of the American Statistical Association 74, 427-431. 
Dvir, E. and K. Rogoff (2014). Demand effects and speculation in oil markets: Theory and evidence. Journal of International Money and Finance 42, 113-128.

Enders, W. and P. Siklos (2001). Cointegration and threshold adjustment. Journal of Business and Economic Statistics 19, 166-176.

Engle, R. F. and C. W. J. Granger (1987). Cointegration and error correction: Representation, estimation and testing. Econometrica 55, 251-276.

Gambetti, L. and L. Moretti (2017). News, noise and oil price swings. Central Bank of Ireland Research Technical Papers No. 12/RT/17.

Gregory, A. W. and B. E. Hansen (1996). Tests for cointegration in models with regime and trend shifts. Oxford Bulletin of Economics and Statistics 58, 555-560.

Hamilton, J. D. (2009). Causes and consequences of the oil shock of 2007-08. Brookings Papers on Economic Activity 40, 215-283.

Hamilton, J. D. (2018). Measuring global economic activity. manuscript, University of California at San Diego.

Johansen, S. (1990). Maximum likelihood estimation and inference on cointegration-with applications to the demand for money. Oxford Bulletin of Economics and Statistics 52, 169-210.

Juvenal, L. and I. Petrella (2015). Speculation in the oil market. Journal of Applied Econometrics 30, 621-649.

Kilian, L. (2008). Exogenous oil supply shocks: How big are they and how much do they matter for the u.s. economy? The Review of Economics and Statistics 90, 216-240.

Kilian, L. (2009a). Comment, in Causes and Consequences of the Oil Shock of 2007-08. ed. by J. Hamilton, vol. 40, 215-283.

Kilian, L. (2009b). Not all oil price shocks are alike: disentangling demand and supply shocks in the crude oil market. American Economic Review 99, 1053-1069.

Kilian, L. and D. Murphy (2014). The role of inventories and speculative trading in the global market for crude oil. Journal of of Applied Econometrics 29, 454-478. 
Knittel, C. R. and R. S. Pindyck (2016). The simple economics of commodity price speculation. American Economic Journal: Macroeconomics 8, 85-110.

Kwiatkowski, D., P. C. B. Phillips, P. Schmidt, and Y. Shin (1992). Testing the null hypothesis of stationary against the alternative of a unit root: How sure are we that economic time series have a unit root. Journal of Econometrics 54, 159-178.

Leduc, S., K. Moran, and R. J. Vigfusson (2016). Learning in the oil futures markets: Evidence and macroeconomic implications. International Finance Discussion Papers 1179.

Lippi, F. and A. Nobili (2012). Oil and the macroeconomy: A quantitative structural analysis. Journal of the European Economic Association 10, 1059-1083.

Perron, P. and T. Wada (2009). Let's take a break: Trends and cycles in US real GDP. Journal of Monetary Economics 56, 749-765.

Phillips, P. C. B. and P. Perron (1988). Testing for a unit root in time series regression. Biometrika 75, 335-346.

Prest, B. C. (2018). Explanations for the 2014 oil price decline: Supply or demand? Energy Economics 74, 63-75.

Ratti, R. A. and J. L. Vespignani (2015). OPEC and non-OPEC oil production and the global economy. Energy Economics 108, 364-378.

Sommer, M., A. G. Auclair, A. Fouejieu, I. Lukonga, S. N. Quayyum, A. Sadeghi, G. H. Shbaikat, A. J. Tiffin, and B. Versailles (2016). Learning to live with cheaper oil; policy adjustment in mena and cca oil-exporting countries. IMF Departmental Papers / Policy Papers 16/08, International Monetary Fund.

Uhlig, H. (2005). What are the effects of monetary policy on output? Results from an agnostic identification procedure. Journal of Monetary Economics 52, 381-419.

Uribe, M. (2018). The neo-Fisher effect: Econometric evidence from empirical and optimizing models. NBER working paper 25089. 


\section{A Data Sources}

\section{A.1 Global real activity}

In the related literature, readers have been witnessing hot debates on the best indicator for economics activity at monthly frequency. Kilian (2009b) constructed an index based on the cost of shipping as proxy for global economic activity. Since, this index has been widely used. Hamilton (2018) puts forward many critics against such index and suggests different sources including monthly industrial production for the OECD plus six other major countries. Dvir and Rogoff (2014) declare using the OECD+6 monthly GDP data - available from 1970Q1 — which they consider as the broadest measure of global income available at monthly frequency, including all developed economies as well as the BRIC countries, Indonesia and South Africa. In reality, the series used by the authors corresponds to one of the Composite Leading Indicators (CLIs) that the OECD developed in early 70s to track turning points in economic activity. Further, the OECD used the index of industrial production (IIP) as a reference until 2012. Since then, it is using the OECD declared that the IIP is no more considered as a reliable proxy for GDP and the main rationale was that the share of services has increased substantially in the global activity. Besides, the CLIs is commonly adopted as a qualitative rather than quantitative information on short-term economic movements. Thus, to have a time consistent and better measure of the global economic activity, we propose constructing a Purchasing Power Parity (PPP) converted real quarterly GDP in U.S. dollars for all OECD members plus six emerging countries (Brazil, China, India, Indonesia, Russia, South Africa) aggregated using .

Quarterly OECD and South Africa real GDP in US dollars (current prices, current PPPs, and seasonally adjusted) are extracted from OECD.Stat covering the period from 1973Q1 until 2018Q1. For the remaining countries - namely, Brazil, China, Indonesia, and India - quarterly nominal GDP is available only starting from 1996Q1 (Brazil), 1992Q1 (China), 1996Q2 (India), and 1990Q1 (Indonesia). To construct the earlier periods' observations, we first use annual data from the World Bank Indicators database for all countries in local currencies. Then, we transform the annual GDP data to PPP measure using the implied PPP conversion rate (national currency per international dollar) published in the World Economic Outlook database by the International Monetary Fund. ${ }^{18}$ Then, we use the Litterman frequency conversion method, while using the OECD quarterly GDP as an indicator, to obtain the quarterly GDP for the early periods of each of the five

\footnotetext{
${ }^{18}$ Since the PPP index is only available starting from 1980, we calculate a linear trend based on the 10 subsequent year, which we reversely apply to obtain the index in the previous years up to 1973.
} 
countries. Finally, the global activity variable is constructed by summing the seasonally adjusted OECD and country specific GDP PPP in USD, which we devide by the consumer price index in the US to obtain the it in real terms.

\section{A.2 Oil market variables}

We extracted world oil production data from the U.S. Energy Information Administration's website: http://www.eia.gov/totalenergy/data/monthly/query/mer_data_excel.asp?table= T11.01B. The available data is presented in thousands of barrel per day at monthly frequency from January 1973 to August 2018. To be as accurate as possible, we take into account the difference of number of days of February between common years- where it is 28 days- and leap years- where it is 29 days. After that, we transform the series from monthly to quarterly frequency. We collected OECD petroleum stocks from the same source (http://www.eia.gov/ totalenergy/data/monthly/query/mer_data_excel.asp?table=T11.03). However, as the data is available on monthly frequency from 1988 and on yearly frequency from 1973, we follow Kilian and Murphy (2014), Dvir and Rogoff (2014) and Baumeister and Hamilton (2018) to construct quarterly stocks from 1973Q1 by scaling U.S. crude oil inventory data by the ratio of OECD petroleum inventories over U.S. petroleum inventories.

We constructed our series of Global oil availability in the same way of Dvir and Rogoff (2014). Oil availability is measured as the sum of global stock of the previous quarter and the production of the current quarter.

For nominal oil prices, we use U.S. Crude Oil Imported Acquisition Cost by Refiners (Dollars per Barrel) from the U.S. Energy Information Administration as in Dvir and Rogoff (2014). The authors suggest that this series is more stable comparing to alternative ones, as it did not witnessed regulatory pressure during 70s and early 80s like West Texas Intermediate (WTI). The data ranges from January 1974 to October 2018 and was downloaded from . Finally, we deflate nominal oil prices and global GDP by the U.S. consumer price index for All Urban Consumers from Federal Reserve Economic Data. Federal Reserve Bank of St. Louis website: https://fred.stlouisfed.org (All Items, Index 1982-1984=100, Quarterly, Seasonally Adjusted) 


\section{Figure A.1: Historical Data}
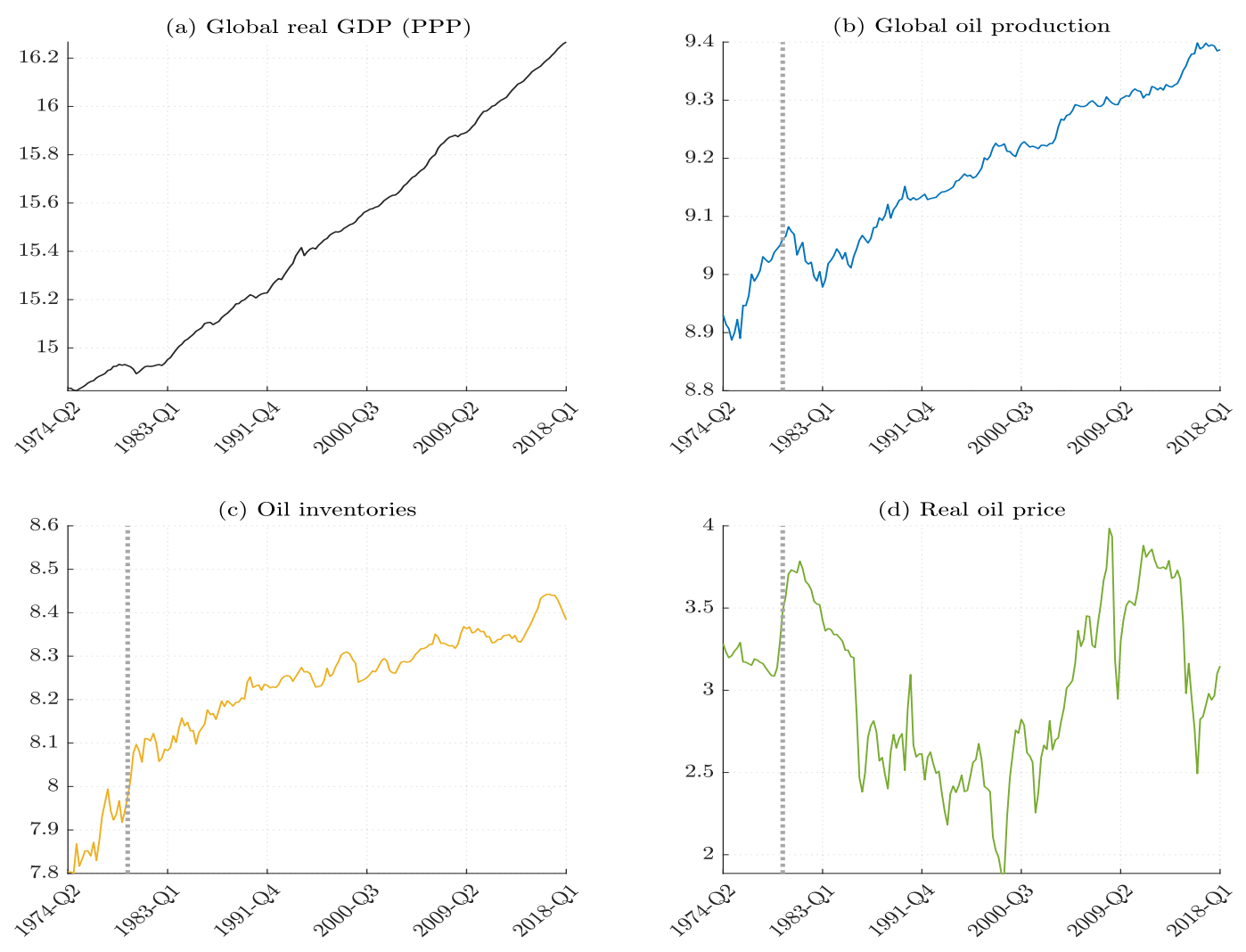

\section{B Unit Roots and Cointegration}

\section{B.1 Unit Roots}

We begin our empirical exercise by testing the non-stationarity in our data series. Using regular unit roots including ADF (Dickey and Fuller, 1979), and PP (Phillips and Perron, 1988), KPSS (Kwiatkowski et al., 1992) could be misleading. Those tests ignore any potential structural break in the series (see the discussion in Baum, 2004). ${ }^{19}$ We implement Clemente et al. (1998) unit root with structural breaks to avoid biased results and to deal with this kind of problem. The test provides the user with information about two potential structural breaks points in the series. Further, it suggests two different models, namely the additive outliers (AO) model and the innovational outliers (IO) model. Each model has his own characteristics. The (AO) model captures a sudden change in the mean of a series, while the (IO) model is more suitable to describe a gradual shift.

\footnotetext{
${ }^{19}$ We still run those test for the endogenous variables of the model and they confirm the presence of a unit root.
} 
Table A.1 describes results of Clemente et al. (1998) test. It shows that none of the 5 test statistics of considered series exceed their approximate 5 percent critical values series (at level), even though the t-statistics for both time break are very significant. This is true in both model (AO and IO). Thus, results indicate the existence of unit root and significant level shifts in all the series. We applied the same test on all series at first difference and we confirmed that variables are stationary and integrated of order $1 .^{20}$

Table A.1: Clemente-Montanes-Reyes Unit Root Test with Structural Breaks

\begin{tabular}{|c|c|c|c|c|c|c|c|c|}
\hline \multirow[t]{2}{*}{ Variable } & \multicolumn{4}{|c|}{ Additive outliers } & \multicolumn{4}{|c|}{ Innovative outliers } \\
\hline & $\begin{array}{l}\text { t-stat. } \\
(\rho=1)\end{array}$ & TB1 & TB2 & $\begin{array}{l}\text { Unit } \\
\text { root }\end{array}$ & $\begin{array}{l}\text { t-stat. } \\
(\rho=1)\end{array}$ & TB1 & TB2 & $\begin{array}{l}\text { Unit } \\
\text { root }\end{array}$ \\
\hline$x_{t}$ & $-2.887(2)$ & 1995Q1*** & $2008 \mathrm{Q} 1^{* * *}$ & yes & $-1.388(5)$ & $1982 Q 2^{* * *}$ & $2003 \mathrm{Q} 1^{* *}$ & yes \\
\hline$z_{t}$ & $-2.830(4)$ & $1988 Q 4^{* * *}$ & $2002 \mathrm{Q} 4^{* * *}$ & yes & $-3.305(5)$ & $1987 Q 1^{* * *}$ & 2003Q1 $1^{* * *}$ & yes \\
\hline$i_{t}$ & $-3.841(4)$ & $1978 Q 3^{* * *}$ & $1990 Q 3^{* * *}$ & yes & $-4.467(4)$ & $1978 Q 4^{* *}$ & 1996Q1*** & yes \\
\hline$p_{t}$ & $-4.957(1)$ & $1986 \mathrm{Q} 4^{* * *}$ & $2004 \mathrm{Q} 4^{* * *}$ & yes & $-4.750(3)$ & $1985 \mathrm{Q}^{* * *}$ & $2003 \mathrm{Q} 3^{* * *}$ & yes \\
\hline
\end{tabular}

Note: Lag order $\mathrm{k}$ is between the parentheses. The 5 percent critical value for both model to reject the null of unit root test is -5.490 . The stars ${ }^{* *},{ }^{* *}$ indicate significance of the time break at 1 and 5 percent level, respectively.

\section{B.2 Cointegration}

To test whether oil variables are cointegrated or not, we use Gregory and Hansen (1996) cointegration test, which accounts for endogenous structural break in the cointegrating equation. Gregory and Hansen (1996) demonstrates that results of most usual cointegration test including Engle and Granger (1987), Johansen (1990) and Enders and Siklos (2001) are biased if the series contains structural break. Gregory and Hansen (1996) recommend four models:

- Model 1: Level Shift (C)

- Model 2: Level Shift with Trend (C/T)

- Model 3: Regime Shift Where Intercept and Slope coefficients Change (C/S)

- Model 4: Regime Shift Where Intercept, Slope Coefficients and Trend Change (C/S/T)

\footnotetext{
${ }^{20}$ Results of Clemente-Montañés-Reyes unit root test at first difference are available upon request.
} 
Gregory and Hansen (1996) approach is an extension of Engle and Granger (1987) which tests the null hypothesis of no cointegration against the alternative of cointegration while taking into account one structural break at an unknown date. In other words, the structural break is endogenously detected. Authors propose three statistics namely $\mathrm{ADF}^{*}, \mathrm{Z}_{t}^{*}$, and $\mathrm{Z}_{\alpha}^{*}$, which are extensions of the traditional ADF and Phillips test type of unit root on the residuals.

Table A.2: Cointegration: Oil Variables

\begin{tabular}{ccccc}
\hline Test & Break & \multicolumn{2}{c}{ Asymptotic Critical Values } \\
\cline { 3 - 5 } Statistic & Date & $1 \%$ & $5 \%$ & $10 \%$ \\
\hline
\end{tabular}

Model 1: Change in Level

$\begin{array}{lccccc}\mathrm{ADF}^{*} & -5.86 & 1980 \mathrm{Q} 3 & -5.44 & -4.92 & -4.69 \\ \mathrm{Z}_{t}^{*} & -9.58 & 1980 \mathrm{Q} 3 & -5.44 & -4.92 & -4.69 \\ \mathrm{Z}_{\alpha}^{*} & -109.72 & 1980 \mathrm{Q} 3 & -57.01 & -46.98 & -42.49\end{array}$

Model 2: Change in Level and Trend

$\begin{array}{lccccc}\mathrm{ADF}^{*} & -6.32 & 1980 \mathrm{Q} 3 & -5.8 & -5.29 & -5.03 \\ \mathrm{Z}_{t}^{*} & -10.06 & 1980 \mathrm{Q} 3 & -5.8 & -5.29 & -5.03 \\ \mathrm{Z}_{\alpha}^{*} & -118.92 & 1980 \mathrm{Q} 3 & -64.77 & -53.92 & -48.94\end{array}$

Model 3: Change in Regime

$\begin{array}{lccccc}\mathrm{ADF}^{*} & -5.81 & 1980 \mathrm{Q} 3 & -5.97 & -5.5 & -5.23 \\ \mathrm{Z}_{t}^{*} & -10.24 & 1980 \mathrm{Q} 3 & -5.97 & -5.5 & -5.23 \\ \mathrm{Z}_{\alpha}^{*} & -122.77 & 1980 \mathrm{Q} 3 & -68.21 & -58.33 & -52.85\end{array}$

Model 4: Change in Regime and Trend

\begin{tabular}{lccccc} 
ADF$^{*}$ & -5.81 & $1980 \mathrm{Q} 3$ & -5.97 & -5.5 & -5.23 \\
$\mathrm{Z}_{t}^{*}$ & -10.24 & $1980 \mathrm{Q} 3$ & -5.97 & -5.5 & -5.23 \\
$\mathrm{Z}_{\alpha}^{*}$ & -122.77 & $1980 \mathrm{Q} 3$ & -68.21 & -58.33 & -52.85 \\
\hline
\end{tabular}

In the first step, we implement Gregory and Hansen (1996) approach to test the null hypothesis of no cointegration against the alternative between oil variables namely World availability, Global inventories and real oil prices. Results of the four models are presented in Table A.2. In the second step, we test the no cointegration hypothesis against the alternative between oil market variables 
and the global GDP. This is important to check whether oil market variables and global GDP share the same sources non-stationarity or not. Results of the four models are presented in Table A.3.

Table A.2 reveals that the absolute value of the three tests statistics (in all four models) are greater than its critical values at 1 percent. Thus, we can reject the null hypothesis of no cointegration and accept the alternative. Moreover, all four models suggest 1980Q3 as break date. ${ }^{21}$

Table A.3: Cointegration: Oil Variables + Global GDP

\begin{tabular}{lccccc}
\hline & Test & Break & \multicolumn{3}{c}{ Asymptotic Critical Values } \\
\cline { 4 - 6 } & Statistic & Date & $1 \%$ & $5 \%$ & $10 \%$ \\
\multicolumn{6}{c}{ Model 1: Change in Level } \\
ADF $^{*}$ & -4.16 & $2004 q 2$ & -5.77 & -5.28 & -5.02 \\
$\mathrm{Z}_{t}^{*}$ & -4.38 & $2003 \mathrm{q} 3$ & -5.77 & -5.28 & -5.02 \\
$\mathrm{Z}_{\alpha}^{*}$ & -31.35 & $2003 \mathrm{q} 3$ & -63.64 & -53.58 & -48.65
\end{tabular}

Model 2: Change in Level and Trend

$\begin{array}{llllll}\mathrm{ADF}^{*} & -4.52 & 2004 \mathrm{q} 1 & -6.05 & -5.57 & -5.33 \\ \mathrm{Z}_{t}^{*} & -4.97 & 2004 \mathrm{q} 3 & -6.05 & -5.57 & -5.33 \\ \mathrm{Z}_{\alpha}^{*} & -40.92 & 2004 \mathrm{q} 3 & -70.27 & -59.76 & -54.94\end{array}$

Model 3: Change in Regime

$\begin{array}{llllll}\mathrm{ADF}^{*} & -4.84 & 2003 \mathrm{q} 1 & -6.51 & -6 & -5.75 \\ \mathrm{Z}_{t}^{*} & -5.25 & 2003 \mathrm{q} 1 & -6.51 & -6 & -5.75 \\ \mathrm{Z}_{\alpha}^{*} & -45.95 & 2003 \mathrm{q} 1 & -80.15 & -68.94 & -63.42\end{array}$

Model 4: Change in Regime and Trend

\begin{tabular}{lccccc}
$\mathrm{ADF}^{*}$ & -4.95 & $2002 \mathrm{q} 1$ & -6.89 & -6.32 & -6.16 \\
$\mathrm{Z}_{t}^{*}$ & -5.9 & $2003 \mathrm{q} 1$ & -6.89 & -6.32 & -6.16 \\
$\mathrm{Z}_{\alpha}^{*}$ & -55.39 & $2003 \mathrm{q} 1$ & -90.84 & -78.87 & -72.75 \\
\hline
\end{tabular}

However, when testing the cointegration between oil variables and global GDP using the same approach, the absolute values of three test statistics (in all four models) are lower than its critical values, even at 10 percent (see Table A.3). Thus, we cannot reject the null hypothesis of no cointe-

\footnotetext{
${ }^{21}$ We have also ran Johansen's cointegration test and found that there is at most one cointegrating equation.
} 
gration. Further, the date breaks are different among the alternative models. These results confirm our guess that sources of non-stationarity between oil variables and Global GDP are different.

\section{Estimated Model}

To identify the transitory and permanent shocks in the model, we adapt the methodology proposed by Uribe (2018) in the context of identification of transitory and permanent monetary shocks, which allows identifying shocks with sign restrictions along with using the Kalman filter to account for unobserved variables - more shocks than endogenous variables in the augmented SVAR model specification.

Let $y_{t}$ be a vector collecting the endogenous variables defined as $y_{t} \equiv\left[\begin{array}{llll}x_{t} & z_{t} & i_{t} & p_{t}\end{array}\right]^{\prime}$, where $x_{t}$ denotes the logarithm of real global output, $z_{t}$ the logarithm of global oil production, $i_{t}$ the logarithm of global oil inventories, and $p_{t}$ the logarithm of global real oil price. In order to explicitly account for shocks to the trend - oil supply and demand - consistently with the results of the cointegration tests, we define the transformed vector of endogenous variables, $\tilde{y}_{t}$, as follows

$$
\tilde{y}_{t} \equiv\left[\begin{array}{c}
x_{t}-\Psi_{t}^{d} \\
z_{t}-\Psi_{t}^{s} \\
i_{t}-\Psi_{t}^{s} \\
p_{t}-\Psi_{t}^{s}
\end{array}\right]
$$

Let $\hat{y}_{t}$ denote the deviation of $\tilde{y}_{t}$ from its unconditional mean: $\hat{y}_{t} \equiv \tilde{y}_{t}-\mathrm{E}\left(\tilde{y}_{t}\right)$

The law of motion of $\hat{y}_{t}$ takes the autoregressive form

$$
\hat{y}_{t}=\sum_{j=1}^{L} A_{j} \hat{y}_{t-j}+B u_{t}
$$

where $u_{t} \equiv\left[\begin{array}{lllll}\psi_{t}^{s} & \phi_{t}^{s p} & \phi_{t}^{s} & \psi_{t}^{d} & \phi_{t}^{d}\end{array}\right]^{\prime}, \psi_{t}^{s} \equiv \Delta \Psi_{t}^{s}-\mathrm{E}\left(\Delta \Psi_{t}^{s}\right)$, and $\psi_{t}^{d} \equiv \Delta \Psi_{t}^{d}-\mathrm{E}\left(\Delta \Psi_{t}^{d}\right)$; with $\Delta$ denoting the time-difference operator. The objects $A_{j}$, for $j=1, \ldots, L$, are 4-by-4 matrices of coefficients, $B$ is a 4-by-5 matrix of coefficients, and $L$ is a scalar denoting the lag length of the empirical model. The vector $u_{t}$ is assumed to follow a stationary process of the form

$$
u_{t+1}=\kappa d_{t+1}+\rho u_{t}+\omega \varepsilon_{t+1}
$$

where $\rho$ is a 5-by-5 diagonal matrix of coefficients in $[0,1), \omega$ is a 5-by-5 diagonal matrix capturing the variances of the innovations, and $\varepsilon_{t+1}$ is a 5-by-1 i.i.d. normal shocks with variances equal to 1. 
The observable variables used in the estimation of the empirical model are growth rates expressed in percent per quarter of global output, global oil production, inventories and real oil prices. The observables variables are linked to the variables included in the unobservable system Equations (5) and (6) through the following relations

$$
\begin{aligned}
\Delta x_{t} & =\Delta \Psi^{d}+\hat{x}_{t}-\hat{x}_{t-1}+\psi_{t}^{d} \\
\Delta z_{t} & =\Delta \Psi^{s}+\hat{z}_{t}-\hat{z}_{t-1}+\psi_{t}^{s} \\
\Delta i_{t} & =\Delta \Psi^{s}+\hat{i}_{t}-\hat{i}_{t-1}+\psi_{t}^{s} \\
\Delta p_{t} & =\Delta \Psi^{s}+\hat{p}_{t}-\hat{p}_{t-1}+\psi_{t}^{s}
\end{aligned}
$$

We denote $o_{t}$ be the vector of variables observed in quarter $t$, which corresponds to $o_{t}=$ $\left[\begin{array}{llll}\Delta x_{t} & \Delta z_{t} & \Delta i_{t} & \Delta p_{t}\end{array}\right]^{\prime}$. The state-space representation of the system composed of Equations (5) to (7) can be written as follows:

$$
\begin{gathered}
\zeta_{t+1}=C \zeta_{t}+D \varepsilon_{t+1} \\
o_{t}=G^{\prime}+H^{\prime} \zeta_{t}
\end{gathered}
$$

where $\zeta_{t}=\left[\begin{array}{lllllll}\hat{y}_{t} & \hat{y}_{t-1} & \ldots & \hat{y}_{t-L+1} & u_{t} & d_{t}\end{array}\right]^{\prime}$. The matrices $C, D, G$, and $H$ are known functions of $A_{i}, i=$ $1, \ldots L, B, \rho, \omega, \mathrm{E}\left(\Delta \Psi_{t}^{d}\right)$, and $\mathrm{E}\left(\Delta \Psi_{t}^{s}\right)$. More specifically, we define $A \equiv\left[A_{1} \cdots A_{L}\right] I_{j}$ as an identity matrix of order $j, \emptyset_{j}$ is a square matrix of order $j$ with all elements equal to zero, while $\emptyset_{i, j}$ denotes a matrix of order $i$ by $j$ with all entries equal to zero. Further, let $L, S$, and $V$ denote, respectively, the number of lags $(=2)$, the number of shocks $(=4)$, and the number of endogenous variables included in the empirical model (=4). Hence, for $L \geq 2$, we have

$$
\begin{aligned}
& C=\left[\begin{array}{ccc}
A & B \rho & \emptyset_{V, 1} \\
{\left[I_{V(L-1)} \emptyset_{V(L-1), V}\right]} & \emptyset_{V(L-1), S} & \emptyset_{V(L-1), 1} \\
\emptyset_{S, V L} & \rho & {\left[-\kappa \emptyset_{(S-1), 1}\right.}
\end{array}\right], D=\left[\begin{array}{c}
B \omega \\
\emptyset_{V(L-1), S} \\
\omega \\
\emptyset_{1, V L} \\
\emptyset_{1, S}
\end{array}\right] \\
& G=\left[\mathrm{E}\left(\Delta \Psi_{t}^{d}\right) \mathrm{E}\left(\Delta \Psi_{t}^{s}\right) \mathrm{E}\left(\Delta \Psi_{t}^{s}\right) \mathrm{E}\left(\Delta \Psi_{t}^{s}\right)\right], \text { and } H^{\prime}=\left[\begin{array}{lll}
M_{\zeta} & \emptyset_{V, V(L-2)} & M_{u}
\end{array}\right]
\end{aligned}
$$

where the matrices $M_{\zeta}$ and $M_{u}$ take the form

$$
M_{\zeta}=\left[\begin{array}{ccccccccc}
1 & 0 & 0 & 0 & -1 & 0 & 0 & 0 & 0 \\
0 & 1 & 0 & 0 & 0 & -1 & 0 & 0 & 0 \\
0 & 0 & 1 & 0 & 0 & 0 & -1 & 0 & 0 \\
0 & 0 & 0 & 1 & 0 & 0 & 0 & -1 & 0
\end{array}\right] \text { and } M_{u}=\left[\begin{array}{ccccc}
0 & 0 & 0 & 1 & 0 \\
1 & 0 & 0 & 0 & 0 \\
1 & 0 & 0 & 0 & 0 \\
1 & 0 & 0 & 0 & 0
\end{array}\right]
$$

